Revista Brasileira de Informática na Educação - RBIE Brazilian Journal of Computers in Education (ISSN online: 2317-6121; print: 1414-5685) http://br-ie.org/pub/index.php/rbie

Submission: 09/Feb/2021;

Camera ready: 19/Jun/2021; $1^{\text {st }}$ round notif.: $10 / \mathrm{Mar} / 2021$

Edition review: 23/Jun/2021;
New version: 26/Apr/2021; Available online: 28/Jun/2021; $2^{\text {nd }}$ round notif.: $17 / \mathrm{May} / 2021$;

Published: 28/Jun/2021

\title{
JEDi - Um Jogo Educacional Digital para Apoiar a Capacitação Discente na Identificação de Fake News Escritas em Língua Portuguesa: Estudos de Caso nos Ensinos Médio e Superior
}

\section{JEDi - A Digital Educational Game to Support Student Training in Identifying Portuguese Written Fake News: Case Studies in High-School and Undergraduate Scenarios}

Claudio A. Passos

Instituto Militar de Engenharia (IME)

cpassos.cp2@gmail.com

Paulo M. S. Freire

Instituto Militar de Engenharia (IME)

paulomsfreire@ime.eb.br
Flávio Roberto Matias da Silva

flavio.matias@ime.eb.br

Ronaldo R. Goldschmidt

Instituto Militar de Engenharia (IME)

ronaldo.rgold@ime.eb.br
Isabel Fernandes

Centro Universitário Uniamérica isabel@uniamerica.br

\begin{abstract}
Resumo
Uma das estratégias para combater o crescente problema das fake news é capacitar pessoas para identificar esse tipo de notícia. Embora existam iniciativas em que tal capacitação é apoiada por jogos educacionais digitais (JED), os JED utilizados não dispõem de notícias escritas em Língua Portuguesa. Para suprir esta lacuna, o artigo apresenta o JEDi, um JED voltado à capacitação de estudantes na identificação de notícias falsas, divulgadas de forma intencional e no idioma português. O JEDi se desenrola em um tabuleiro a ser percorrido pelos jogadores na medida em que esses conseguem discernir entre notícias verdadeiras e falsas. Vence a partida, o jogador que alcançar o final do tabuleiro primeiro. A ideia é que, na medida em que joguem diversas partidas, os jogadores desenvolvam a capacidade de reconhecer notícias falsas. Ao persistir os resultados individuais dos jogadores, o JEDi permite analisar, com técnicas de mineração de dados, o desempenho longitudinal de cada jogador e, portanto, sua efetividade como jogo na capacitação para reconhecer fake news. O artigo relata a aplicação do JEDi em um estudo de caso com alunos do Ensino Médio e outro com alunos da Educação Superior. Resultados quantitativos e qualitativos obtidos nos dois estudos apontam para a efetividade do JEDi como instrumento de capacitação na identificação de fake news.
\end{abstract}

Palavras-chave: Educação Midiática; Jogos Educacionais Digitais; Detecção de Fake News.

\begin{abstract}
One of the strategies to combat the fake news problem is to train people to identify this kind of news. Although there are initiatives where such training is supported by digital educational games (DEG), the DEG used do not have portuguese-written news. To fill this gap, this article presents JEDi, a JED that trains students to identify intentionally disseminated, portuguese-written false news. JEDi takes place on a board to be traversed by the players as they discern between true and false news. The winner is the player that reaches the board's end first. The idea is that, as they play several times, players develop the ability to recognize fake news. By storing the players' individual results, JEDi allows analyzing, with data mining techniques, each player's longitudinal performance and, therefore, its effectiveness in false news recognition training. This paper reports the use of JEDi in a case study with high school and another with undergraduate students. Quantitative and qualitative results obtained in both studies point to JEDi's effectiveness as a fake news detection training instrument.
\end{abstract}

Keywords: Media Education; Digital Educational Games; Fake News Detection.

Cite as: Passos, C. A., Silva, F. R. M., Fernandes, I., Freire, P. M. S., Goldschmidt, R. R. (2021). JEDi-Um Jogo Educacional Digital para Apoiar a Capacitação Discente na Identificação de Fake News Escritas em Língua Portuguesa: Estudos de Caso nos Ensinos Médio e Superior. Revista Brasileira de Informática na Educação, 29, 634-661. DOI: 10.5753/RBIE.2021.29.0.634 . 


\section{Introdução}

O problema de combater fake news (i.e., notícias falsas divulgadas de forma intencional) não é recente (P. M. S. Freire \& Goldschmidt, 2019). Contudo, sua complexidade vem aumentando em função do crescimento do volume e da velocidade de divulgação dessas notícias proporcionado pelos meios digitais de divulgação de notícias (MDDN), em especial, por redes sociais virtuais (RSV) (Shu, Sliva, Wang, Tang, \& Liu, 2017), tais como Twitter e Facebook.

Como exemplo do poder de influência das fake news, pode-se enfatizar o caso da pandemia de COVID-19 (Coronavirus Disease-19) que matou centenas de milhares de pessoas no ano de 2020 ao redor do mundo ${ }^{1}$. Inúmeras fake news têm sido divulgadas em MDDN sobre essa doença (Mejova \& Kalimeri, 2020). Tais divulgações têm dificultado, de forma significativa, o esclarecimento da população sobre a disseminação da pandemia e sobre as medidas de enfrentamento da doença a serem adotadas.

Diferentes segmentos da sociedade têm pesquisado como combater fake news disponibilizadas em MDDN, em especial nas RSV (Zhou, Zafarani, Shu, \& Liu, 2019). Como consequência, algumas ações mitigadoras estão sendo potencializadas. Assim, podem-se destacar a criação de legislação punitiva ${ }^{2}$, os serviços de checagem de fatos e o emprego de abordagens computacionais nos MDDN (P. Freire \& Goldschmidt, 2020).

Apesar da importância dessas ações que objetivam enfraquecer a divulgação das fake news, uma das principais estratégias de combate a esse tipo danoso de notícia é pelo desenvolvimento, na sociedade, de uma capacidade crítica, isenta de preconceitos, ideologias e interesses, que possibilite uma melhor distinção entre as informações verdadeiras e falsas nos meios digitais (UNESCO, 2019). Uma das principais formas de prover tal capacidade, assim como enfatizar a preocupação em divulgar somente informações verificadamente verdadeiras, é por meio de iniciativas educacionais. Segundo UNESCO (2016), tais iniciativas educacionais estão presentes na alfabetização midiática e informacional, em que um de seus principais objetivos é capacitar as pessoas para avaliar criticamente os conteúdos digitais. Neste contexto de alfabetização, merecem destaque os jogos educacionais digitais $\left(\mathrm{JED}^{3}\right.$ ) que, conforme indicado por Paz, Franco, de Castro Bertagnolli, and Costa (2018), têm sido adotados como ferramentas de apoio ao aprendizado, nos diferentes níveis de ensino.

Embora existam estudos voltados à experimentação de JED como instrumentos de capacitação de pessoas na identificação de fake news, até onde foi possível observar, os JED utilizados não dispõem de notícias escritas em Língua Portuguesa. Diante deste cenário, pode-se levantar a seguinte questão de pesquisa: JED podem ser utilizados para capacitação discente ${ }^{4}$ na identificação de fake news escritas em Português?

Assim sendo, o presente trabalho teve como objetivo buscar evidências experimentais que

\footnotetext{
${ }^{1}$ www.who.int/emergencies/diseases/novel-coronavirus-2019

${ }^{2}$ https://www12.senado.leg.br/noticias/materias/2020/06/02/nova-versao-de-lei-contra-fake-news-tera-restricoes -a-contas-anonimas-e-mais-poder-a-denuncias-de-usuarios

${ }^{3}$ No presente artigo, o acrônimo JED está sendo aplicado indistintamente para as formas singular e plural de citação a jogos educacionais digitais.

${ }^{4}$ Outra providência adotada no presente manuscrito com o objetivo evitar a repetição de texto, foi a utilização da palavra "aluno", "estudante"e "discente"como sinônimos.
} 
respondessem positivamente à questão de pesquisa levantada. Para tanto, propôs o JEDi, um jogo educacional digital voltado à capacitação de estudantes na identificação de fake news escritas em Língua Portuguesa.

Inspirado no clássico "Jogo da Trilha", o JEDi foi projetado para se desenrolar em um tabuleiro. Na medida em que sorteiam os dados para percorrer esse tabuleiro, os jogadores se deparam com notícias e apontam se as mesmas são fake ou não. Vence a partida o primeiro jogador que alcançar o final do tabuleiro. Ao persistir todas as escolhas e os resultados individuais dos jogadores em cada partida, o JEDi permite analisar, por meio de técnicas de mineração de dados, o desempenho longitudinal individual e, portanto, a sua efetividade como jogo em contribuir para o seu propósito de capacitação para o reconhecimento de fake news.

Outra característica do JEDi é o fato de o jogo acessar uma base de notícias fake e não fake atualizada de forma contínua ao longo do tempo. A atualização da base é feita a partir das agências de checagem de fatos, ou seja, são notícias que circulam nas redes sociais. O processo de recuperação e atualização da base de dados encontra-se descrito em Silva (2020). Ao fazer uso dessas notícias, o JEDi estimula os alunos a se manterem informados sobre atualidades do mundo contemporâneo, ao mesmo tempo em que exercita a capacidade crítica dos discentes na identificação de notícias falsas.

Para indicar a viabilidade do jogo diante do problema de se identificar fake news foram realizados dois estudos de caso. O primeiro com quarenta e três alunos do ensino médio de uma escola da rede privada de educação do município de Foz do Iguaçu-PR. O segundo envolveu vinte e nove alunos de uma instituição de ensino superior pública do município do Rio de Janeiro-RJ.

Resultados quantitativos e qualitativos obtidos em ambos os estudos de caso revelaram evidências estatísticas que apontam para a efetividade do JEDi como instrumento de capacitação discente na identificação de fake news. Também foi possível constatar, por meio de uma pesquisa de opinião, uma boa receptividade do jogo não somente junto aos alunos, mas também entre os docentes e as equipes diretivas das instituições envolvidas.

Este artigo está organizado em mais cinco seções. A Seção 2 apresenta uma fundamentação teórica para facilitar o entendimento de alguns pontos importantes deste trabalho tais como mineração de regras de associação e caracterização de fake news. A Seção 3, por sua vez, descreve os principais trabalhos relacionados com o tema desta pesquisa. O JEDi é apresentado na Seção 4 e os estudos de caso realizados a partir desse jogo são expostos na Seção 5, detalhando a metodologia utilizada, a base de dados do JEDi, a dinâmica dos estudos de caso, o pré-processamento dos dados coletados nas partidas e os resultados obtidos. A Seção 6 destaca as contribuições e os resultados mais relevantes obtidos pela presente pesquisa, além de apontar lacunas e iniciativas de trabalhos futuros.

\section{Fundamentação Teórica}

Esta seção tem como objetivo apresentar algumas informações relevantes relacionadas às fake news e suas características, além de descrever conceitos básicos da tarefa de mineração de dados utilizada neste trabalho: a mineração de regras de associação. 


\subsection{Fake News}

Como a utilização da expressão fake news é relativamente recente, a sua caracterização se faz necessária. Para tal, são agrupadas as diferentes interpretações para fake news, assim como são categorizadas as razões que levam ao seu comportamento disseminativo nas redes sociais. Além disso, como todas as diferentes interpretações convergem em considerar as fake news como falsas, se torna importante procurar conceituar o que é verdade.

\subsubsection{Caracterização}

Apesar da originalidade da expressão, as fake news não surgiram com o uso dos MDDN. Haja vista que, mesmo com as mídias tradicionais, já existiam pessoas que, por diferentes razões, divulgavam notícias falsas de forma proposital (Golbeck et al., 2018). Independente do surgimento, devido à contemporaneidade do termo, fake news apresenta diversas definições que podem ser organizadas em dois grupos.

O primeiro grupo considera que o aspecto proposital é fundamental, pois define as fake news como publicações intencionais e verificadamente falsas (Mustafaraj \& Metaxas, 2017), (Shu et al., 2017), (Zhou et al., 2019), (Campan et al., 2017), (Flintham et al., 2018), (Wang et al., 2018), (Zhou \& Zafarani, 2020), (Conroy et al., 2015) e (Reis et al., 2019).

Assim, para esse primeiro grupo, não basta a notícia ser falsa para ser caracterizada como fake news, é também preciso ter sido divulgada intencionalmente. Cabe ressaltar que, apesar de pertencente ao primeiro grupo, o trabalho Zhou and Zafarani (2020) é ainda mais específico em sua definição, pois só considera fake news quando a notícia intencionalmente falsa é divulgada por uma mídia virtual (e.g.: jornal on-line).

O segundo grupo, entretanto, tem uma definição mais genérica. Para esse segmento, as fake news são todas as notícias falsas, independente da sua natureza intencional (Sharma et al., 2019), (Castelo et al., 2019) e (Ajao et al., 2019). Assim, podem considerar como fake news outros tipos de notícia, como, por exemplo, um rumor ${ }^{5}$ detectado como falso após a sua divulgação. Inclusive, notícias falsas podem ser disseminadas por pessoas que acabam por divulgar informações erradas de forma não proposital, seja devido à falta de atualização sobre o assunto ou, até mesmo, por falhas na interpretação sobre o conteúdo abordado.

Este trabalho adota a definição do primeiro grupo. Consequentemente, considera fake news como sendo uma notícia intencionalmente falsa. A principal razão da escolha é que uma notícia propositalmente divulgada tende a ser mais bem elaborada, podendo causar mais malefícios aos usuários.

\subsubsection{Comportamento Disseminativo}

A disseminação e, consequente, divulgação de uma notícia se inicia pela sua publicação e provável propagação denominada de Efeito de Câmara de Eco (Shu et al., 2017). Dessa forma, é importante destacar o momento no qual uma notícia pode ser caracterizada como fake news. Basicamente,

\footnotetext{
${ }^{5}$ Rumor é uma informação que não foi verificada como verdadeira ou falsa ao ser divulgada (Vosoughi, Mohsenvand, \& Roy, 2017)
} 
uma notícia intencionalmente falsa pode surgir de três formas. A primeira é quando a fake news é iniciada (publicada) em uma mídia virtual, podendo, posteriormente, ser republicada em uma rede social ou em um aplicativo de troca de mensagens. Na segunda forma, esse tipo de notícia é iniciada (publicada) diretamente na rede social ou em um aplicativo de troca de mensagens. Independente de ter surgido ou não na rede social ou em um aplicativo de troca de mensagens, a partir da sua chegada, essa notícia pode ser potencializada pela sua propagação. A terceira é quando uma notícia não fake é publicada, porém se torna fake, a partir do seu espalhamento, de acordo com as contribuições intencionalmente falsas feitas durante a sua propagação (P. Freire \& Goldschmidt, 2020).

Independente do momento de criação, as razões que potencializam a divulgação intencional das notícias falsas nos MDDN podem ser divididas em três categorias. A primeira tem relação com a suscetível incapacidade humana para avaliar criticamente os conteúdos digitais (UNESCO, 2016), que pode ser ocasionada pelos seguintes fatores (Shu et al., 2017):

- Preferem receber informações que confirmem as suas opiniões sem, necessariamente, verificarem a veracidade da notícia;

- Tendem a aceitar as informações não pela análise da verdade, mas pela relação de ganhos e perdas que a notícia pode trazer para elas;

- Tendem a avaliar as informações sem a busca da veracidade, pois acabam acompanhando a aceitação dos outros.

A segunda categoria é a carência de legislação punitiva, uma das alegações para tal fato é que as referidas leis poderiam cercear a liberdade de expressão. Já a terceira categoria advém da facilidade de criação de contas nas redes sociais (Conroy et al., 2015). Um aspecto importante inerente à essa facilidade é a criação de contas digitais maliciosas por meio de divulgadores de natureza humana ou computacional (e.g.: humanos e robôs) (Shu et al., 2017).

\subsubsection{Conceituações sobre Verdade}

A conceituação sobre verdade de uma afirmação é ampla, podendo-se destacar a existência de diferentes concepções filosóficas sobre a natureza do conhecimento verdadeiro. Inclusive, tal amplitude pode ser caracterizada pelas concepções ceticista e relativista. A primeira concepção, na sua forma clássica (ou ceticismo pirrônico) defende uma postura suspensiva, haja vista que a multiplicidade de explicações acerca de uma mesma afirmação constitui, por si só, razão suficiente para nada se afirmar de forma absoluta (Empirico, 1997). A segunda concepção, baseada no relativismo absoluto, aceita diferentes verdades para uma mesma afirmação (Rodrigues, 2013). Inclusive, é possível ressaltar a refutação tanto do ceticismo quanto do relativismo, pois é difícil para alguém declarar-se ceticista ou relativista sem se colocar fora ou acima de tal declaração. Isso acontece porque, se uma pessoa declara que "não há verdade absoluta" ou que "todas as verdades são relativas", aparece a dúvida se tal afirmação é ou não, respectivamente, cética ou relativa.

Em outra perspectiva, segundo Sponholz (2009), uma notícia pode conter afirmações descritivas e/ou de juízo de valor. Assim, uma notícia pode ter a verdade constatada tanto pela verificação dos fatos quanto dos argumentos relacionados ao assunto publicado. 


\subsection{Mineração de Regras de Associação}

A expressão mineração de dados é proveniente do termo em inglês Data Mining que corresponde ao nome dado ao processo que busca encontrar padrões recorrentes e detectar relacionamentos novos e potencialmente úteis entre variáveis a partir da exploração de grandes quantidades de dados (Faceli et al., 2011). Para alcançar tal objetivo, utiliza-se de diversos algoritmos, técnicas e tarefas, como a mineração de regras de associação (do inglês, Association Rules Mining - ARM) (Goldschmidt et al., 2015).

A ARM consiste em identificar regras de associação frequentes e válidas em um conjunto de dados (Agrawal et al., 1993). A seguir, encontram-se os conceitos básicos necessários à compreensão desta tarefa.

Seja $D$ um conjunto de dados com $n$ atributos $A_{i}, i=1 . . n$ e $m$ registros de dados $r_{j}, j=1 . . m$. Sejam ainda os conjuntos de valores $V_{A_{i}}=\left\{v_{A_{i, 1}} . . v_{A_{i,\left|V_{A_{i}}\right|}}\right\}$ que contém os valores possíveis para o atributo $A_{i}$, onde $\left|V_{A_{i}}\right|$ representa a quantidade de elementos em $V_{A_{i}}$. Considere, a título ilustrativo, um cenário escolar que disponha de um conjunto de dados $D^{\prime}$ sobre alunos que contenham os atributos TurnoEstudo, PraticaEsporte, DesempenhoEscolar e os conjuntos de valores $V_{\text {TurnoEstudo }}=\{$ Matinal,Vespertino, Integral $\}, V_{\text {PraticaEsporte }}=\{$ Sim,Nao $\}$ e $V_{\text {DesempenhoEscolar }}=\{$ Bom, Regular,Fraco $\}$.

Define-se item em $D$ como sendo toda condição da forma $A_{i}=v_{k}$, onde $v_{k} \in V_{A_{i}}$. No conjunto de dados $D^{\prime}$ abordado no parágrafo anterior, TurnoEstudo $=$ Integral, PraticaEsporte $=$ Sim e DesempenhoEscolar $=$ Bom são exemplos de itens.

Todo item em $D$ pode assumir valor verdadeiro ou falso diante do registro de dados analisado. Diz-se, portanto, que um registro $r$ satisfaz um item $I$ se, e somente se, $I$ assume valor verdadeiro diante de $r$. Retomando novamente o conjunto $D^{\prime}$ do exemplo anterior, considere dois alunos Maria e Carlos, sendo que Maria pratica esporte e Carlos não. Neste caso, enquanto o registro de dados associado a Maria satisfaz o item PraticaEsporte $=$ Sim (i.e., o item assume valor verdadeiro diante do registro de Maria), o registro associado a Carlos não satisfaz o referido item, uma vez que PraticaEsporte $=$ Sim assume valor falso diante de tal registro.

Em seguida, define-se, ainda, um conjunto de itens em $D$ como qualquer conjunto cujos elementos são itens em $D$. Considerando, novamente, o conjunto $D^{\prime}$ do cenário ilustrado acima, $\{$ TurnoEstudo $=$ Integral,PraticaEsporte $=\operatorname{Sim}\}$ e $\{$ DesempenhoEscolar $=$ Bom $\}$ são exemplos de conjuntos de itens em $D^{\prime}$.

Uma regra de associação $R$ de um conjunto $D$ é uma implicação da forma $X \rightarrow Y$, onde $X$ e $Y$ são conjuntos de itens em $D$ tais que $X \cap Y=\emptyset$. Satisfazem a $R_{1}$, todos os registros de dados de $D$ que satisfazem (i.e., tornam verdadeiros) esses três itens ao mesmo tempo. Ainda tomando o cenário ilustrado anteriormente, $R_{1}:\{$ TurnoEstudo $=$ Integral,PraticaEsporte $=$ $\operatorname{Sim}\} \rightarrow\{$ DesempenhoEscolar $=$ Bom $\}$ é uma regra de associação

Uma regra de associação $R: X \rightarrow Y$ é dita frequente (resposta válida) se, e somente se, $\operatorname{Sup}(R)=|X \cup Y| /|D| \geq \operatorname{MinSup}^{6}\left(\right.$ resposta $\left.\operatorname{Conf}(R)=|X \cup Y| /|X| \geq \operatorname{MinConf}^{7}\right)$, onde $X \cup Y$ é o conjunto de registros que satisfazem os itens em $X$ e $Y$ simultaneamente; $\operatorname{Sup}(R)$ e $\operatorname{Conf}(R)$

\footnotetext{
${ }^{6}$ Suporte Mínimo

${ }^{7}$ Confiança Mínima
} 
são, respectivamente, o suporte e a confiança de $R ;|D|$ representa a quantidade total de registros de dados disponíveis no conjunto de dados D; e MinSup e MinConf são hiperparâmetros definidos pelo usuário. Considerando a regra $R_{1}$ exemplificada anteriormente, se o conjunto de dados tem 100 registros no total, dos quais 50 satisfazem simultaneamente aos itens TurnoEstudo $=$ Integral e PraticaEsporte $=$ Sim, mas apenas 45 desses, satisfazem também ao item DesempenhoEscolar $=$ Bom, tem-se que $\operatorname{Sup}\left(R_{1}\right)=45 \%$ e $\operatorname{Conf}\left(R_{1}\right)=90 \%$. Assumindo, por exemplo, MinSup $=10 \%$ e MinConf $=80 \%, R_{1}$ seria considerada uma regra frequente e válida.

Em geral, a tarefa de ARM ocorre em duas etapas (Agrawal et al., 1993). A primeira, de maior custo computacional, busca por conjuntos de itens frequentes que ocorrem simultaneamente no conjunto de dados. A segunda consiste em identificar as regras válidas a partir de cada conjunto de itens considerado frequente na etapa anterior. A execução dessas etapas pode ser realizada várias vezes, na medida em que sejam experimentados diferentes valores dos hiperparâmetros de suporte e confiança mínimos.

Tipicamente, a escolha de valores adequados para os hiperparâmetros das técnicas de mineração de dados não é uma tarefa simples e varia de uma aplicação para outra. No caso da ARM, não é diferente. Valores muito altos de suporte e confiança mínimos podem levar a casos extremos em que nenhuma regra é identificada. Por outro lado, valores muito baixos podem levar a grandes quantidades de regras e, com isso, onerar de sobremaneira a avaliação de todas as regras identificadas. Uma estratégia para calibragem dos valores dos hiperparâmetros da ARM é experimentar primeiro valores de confiança mínima mais elevados (e.g., próximos a 100\%, indicando um alto rigor com a certeza de aplicabilidade da regra) e valores de suporte mínimo mais baixos (e.g., até 5\%, em busca de regras mais raras e, que, portanto, possam trazer relações desconhecidas no domínio da aplicação). Medidas como lift e convicção também podem ser usadas para auxiliar na filtragem de regras de associação interessantes em grandes bases de dados (Faceli et al., 2011).

\section{Trabalhos Relacionados}

Os trabalhos relacionados a este estudo podem ser divididos em dois grupos. O grupo 1 refere-se aos de combate às fake news via processos educativos, ou seja, com o apoio educacional. No grupo 2 estão os trabalhos que relatam jogos como ferramentas educacionais para o desenvolvimento da capacidade crítica em identificar notícias falsas. Para ambos os grupos de trabalhos relacionados, reproduzidos de forma sintetizada nessa seção, os manuscritos foram selecionados entre o conjunto de artigos da revisão sistemática que fundamentou a produção de Silva (2020), cujo foco fora o suporte computacional para a detecção automática de fake news.

Para a seleção dos trabalhos foram consultadas as bibliotecas digitais Scopus Elsevier, Web of Science, ACM (Association for the Computing Machinery) e IEEE (Institute of Electrical and Electronic Engineers) além da ferramenta de recuperação de documentos científicos, o Google Scholar. Nessa última, os pesquisadores utilizaram o índice bibliométrico H5 para apoiar a avaliação da qualidade do manuscrito. As estratégias de busca utilizadas foram 'fake news', 'educação', 'jogos educacionais' e 'jogos educacionais digitais', nos idiomas português e inglês. Esses descritores foram aplicados de forma combinadas com os operadores lógicos 'AND' e 'OR, utilizados nos mecanismos de busca das bases de dados consultadas (Silva, 2020). No conjunto 
resultante dessa revisão sistemática, a seleção de oito trabalhos foi norteada pela contribuição da educação no combate às fake news e pela linha do tempo dos jogos no suporte ao aprendizado para a identificação de notícias falsas.

Assim, quanto às produções revisadas no grupo 1 , foram avaliados quatro trabalhos baseados no apoio educacional no tocante ao combate às fake news. Em Francesco and Leone (2020), discute-se como a aplicação da "Educação Midiática" nas escolas de ensino básico pode contribuir para a identificação desse tipo de notícias. Segundo Auberry (2018), para que estudantes sejam capazes de distinguir entre fake news e notícias verdadeiras com eficácia, torna-se necessário incentivá-los a interagir com as fontes dessas notícias. O estudo de Musgrove, Powers, Rebar, and Musgrove (2018) descreve como identificar notícias intencionalmente falsas em mídias virtuais e os recursos que professores podem utilizar para essa finalidade. O quarto e último trabalho do grupo 1, em Nascimento (2020), busca-se compreender o fenômeno das fake news, relacionando-o com o conceito de mentira organizada.

O grupo 2 contém três trabalhos que, assim como o presente estudo, efetivamente utilizaram jogos como ferramentas educacionais para o desenvolvimento da capacidade crítica das pessoas quanto aos conteúdos digitais. Esses trabalhos foram comparados, conforme descrito na Tabela 1, segundo os seguintes critérios: idioma português (indica se as notícias que o jogo utiliza estão escritas na língua portuguesa), base atualizável (indica se a base de notícias pode ser atualizada), oferece suporte para mineração de dados e o último critério indica se o jogo está em formato digital. A seguir esses trabalhos encontram-se brevemente descritos.

Dois dos três trabalhos mencionados no parágrafo anterior se baseiam na Teoria da Inoculação (Roozenbeek \& van der Linden, 2019a, 2019b), originalmente proposta por McGuire (1964) que compara a divulgação de fake news com a propagação de uma epidemia viral. A base dessa teoria são tentativas de indução de atitudes de resistência à persuasão e à propaganda seja ela enganosa ou não, de maneira análoga à imunização biológica. Ou seja, assim como as injeções que contêm uma dose enfraquecida de um vírus podem conferir resistência a futuras infecções por meio da produção de anticorpos, a teoria da inoculação postula que o mesmo efeito pode ser alcançado com "anticorpos mentais", expondo as pessoas a uma versão enfraquecida de um argumento e refutando, posteriormente, esse mesmo argumento.

Em Roozenbeek and van der Linden (2019a), uma versão ativa da teoria da inoculação é proposta por meio da aplicação de um jogo denominado "The Fake News Game". Nesse jogo, inicialmente, os jogadores são divididos em grupos, mas somente um desses grupos recebe a tarefa ativa de criar notícias sobre uma questão fortemente politizada, usando táticas inerentes a diferentes tipos de produtores de fake news, conforme detalhado em Marwick and Lewis (2017). Logo após essa etapa do jogo, realiza-se uma tarefa de identificação de fake news. A identificação envolve a leitura de notícias fake e não fake, atribuídas aleatoriamente entre todos os jogadores. Os resultados obtidos por esse estudo fornecem informações preliminares, evidenciando que o poder de persuasão das fake news foi atenuado para o grupo de jogadores que realizou a tarefa de criação antes da tarefa de identificação de notícias fake.

Uma outra forma de combater fake news utilizando gameficação foi proposta, por meio do jogo "Bad News Game"8, na qual os jogadores assumem o papel de produtores de notícias e aprendem a dominar seis técnicas comumente utilizadas na produção de desinformação: polariza-

\footnotetext{
${ }^{8}$ https://www.getbadnews.com/\#play
} 
ção, invocação de emoções, disseminação de teorias da conspiração, debochar de pessoas on-line, desviar a culpa de determinada ação e utilizar contas falsas. Uma avaliação em larga escala desse jogo foi realizada com 15.000 participantes e evidências iniciais foram identificadas, indicando que a capacidade das pessoas de detectar e resistir à desinformação melhora após o jogo, independentemente da educação, idade, ideologia política e estilo cognitivo (Roozenbeek \& van der Linden, 2019b).

Criado pela Factchekers.it para o evento Internacional Fact Checking Networking (IFCN), o jogo de RPG (i.e., Role-Playing Game) "Cheque Isso" proposto por Abreu et al. (2018) foi desenvolvido a fim de incentivar o hábito de checagem de informações entre os jovens.

Tabela 1: Comparação entre os trabalhos relacionados na presente pesquisa.

\begin{tabular}{|c|c|c|c|c|}
\hline Jogo & $\begin{array}{c}\text { Idioma } \\
\text { Português }\end{array}$ & $\begin{array}{c}\text { Base } \\
\text { Atualizável }\end{array}$ & $\begin{array}{c}\text { Suporte para } \\
\text { Mineração }\end{array}$ & Digital \\
\hline $\begin{array}{c}\text { The Fake News Game } \\
\text { (Roozenbeek \& van der Linden, 2019a) }\end{array}$ & & & & \\
\hline $\begin{array}{c}\text { Bad News Game } \\
\text { (Roozenbeek \& van der Linden, 2019b) }\end{array}$ & $\mathrm{X}$ & $\mathrm{X}$ & \\
\hline $\begin{array}{c}\text { Cheque Isso } \\
\text { (Abreu et al., 2018) }\end{array}$ & $\mathrm{X}$ & $\mathrm{X}$ & $\mathrm{X}$ & $\mathrm{X}$ \\
\hline $\begin{array}{c}\text { JEDi } i \\
\text { (JED adotado no presente trabalho) }\end{array}$ & & & & \\
\hline
\end{tabular}

Em resumo, pode-se observar que, diferentemente do JEDi proposto neste artigo, nenhum dos jogos indicados apresenta, simultaneamente, notícias escritas em Língua Portuguesa, base de notícias atualizável e recursos de apoio à análise de dados sobre o desempenho dos jogadores. Além disso, apenas um desses jogos, o 'Bad News Game', é, de fato, digital. O jogo foi avaliado e seu propósito educativo difere da proposta do jogo apresentado nesse artigo. O 'Bad News Game' objetiva o treino do jogador enquanto produtor de notícias falsas. O JEDi, por outro lado, apresenta notícias verdadeiras e falsas para que o jogador identifique quais delas são fake news. Além disso, pesquisas foram realizadas em busca do 'Bad News Game' em outros idiomas, porém, nada relacionado à tradução do jogo foi encontrado. A tabela 1 apresenta as comparações dos trabalhos relacionados na pesquisa.

\section{O JEDi}

Acessível a partir da plataforma Memore-net", o "JEDi" é uma versão do "Jogo da Trilha" que propõe uma competição saudável entre os participantes, podendo ser jogado de três formas diferentes. São elas: individualmente; em grupos de no máximo seis jogadores (sendo todos no mesmo computador); em grupos de no máximo seis participantes, sendo cada participante jogando em seu

\footnotetext{
${ }^{9}$ Plataforma colaborativa de apoio à aprendizagem que oferece recursos aos interessados em educação apoiada por computador para compartilhar experiências, realizar práticas de ensino-aprendizagem, aprender e aprimorar ações e políticas pedagógicas no uso das tecnologias da informação e comunicação em sala de aula (Passos, Fernandes, \& Goldschmidt, 2019). Para detalhes, acessar http://memore-net.com.
} 
próprio computador. Trata-se de um JED de tabuleiro que utiliza o mouse e o teclado do computador para que os jogadores acionem o dado e respondam às perguntas propostas, selecionadas aleatoriamente e sem reposição a partir de uma base de dados previamente configurada. As perguntas podem ser acompanhadas de imagens e são apresentadas na forma de múltipla escolha com até quatro opções de respostas.

Por estar integrado à Memore-net, o JEDi pode ter seu conteúdo configurado pelo professor, além de ser capaz de coletar dados sobre o comportamento dos alunos durante as partidas ao longo do tempo. Os dados coletados podem ser posteriormente analisados pelo professor por meio de recursos de mineração de dados, a fim de apoiar o docente na avaliação discente e na identificação de lacunas de aprendizado. A Figura 1(a) apresenta por meio de um diagrama de casos de uso (Bezerra, 2007), uma visão simplificada das principais funcionalidades da Memore-net que são relevantes no contexto do presente artigo e que se encontram comentadas a seguir.
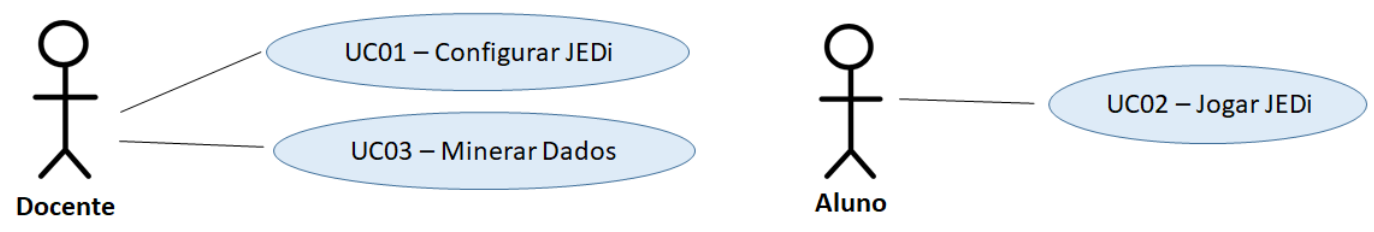

(a)

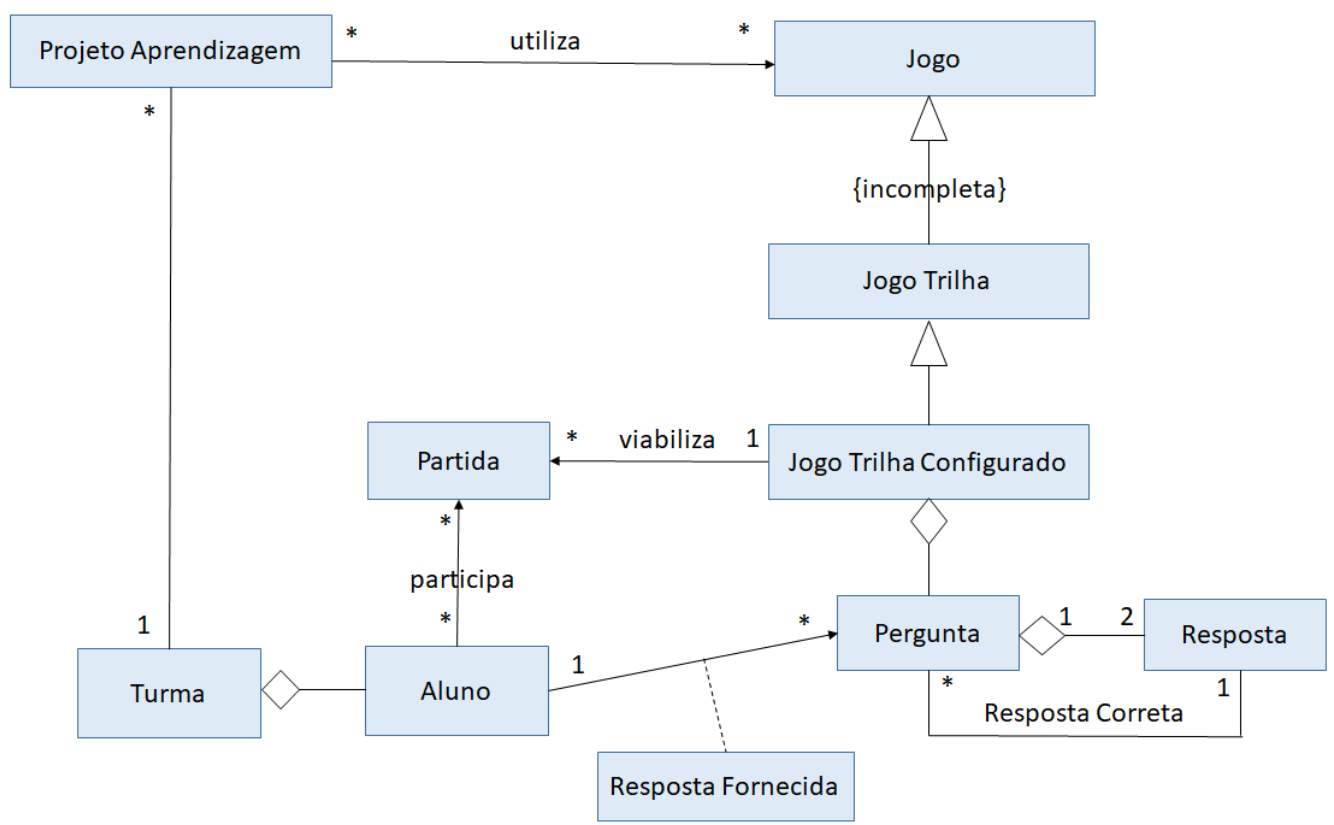

(b)

Figura 1: Modelos Parciais: (a) Funcional e (b) de Dados do JEDi.

Para este trabalho, o JEDi foi configurado de forma a desafiar os jogadores a identificar fake news. Assim, cada pergunta corresponde a uma afirmação cujas respostas possíveis são fake ou não fake. As perguntas são obtidas a partir de um conjunto de dados que contém, para cada pergunta, a data de publicação da notícia, a resposta correta e, se for o caso, alguma imagem associada. A escolha do conjunto de dados a ser utilizado é feita pelo professor, a partir do caso 
de uso UC01. Uma vez configurado, o JEDi pode ser jogado pelos alunos. Sempre que um aluno joga uma partida do jogo (UC02), os dados sobre o seu comportamento de utilização são armazenados no banco de dados do jogo e podem, posteriormente, ser acessados pelo docente por meio de consultas e técnicas de mineração de dados (UC03). Entre as técnicas disponíveis na Memore-net está uma implementação da tarefa de mineração de regras de associação (vide Seção 2.2 para detalhes sobre esta tarefa) que, no contexto de aplicação deste trabalho, busca identificar regras de associação que mostrem a evolução da capacidade discente em diferenciar notícias fake das não fake.

A Figura 1(b) apresenta, um diagrama de classes da UML que contém uma visão parcial do modelo de dados conceitual simplificado (sem atributos) do banco de dados da Memore-net. Por meio deste modelo, percebe-se que as respostas fornecidas pelos alunos diante de cada pergunta ao longo das partidas são armazenadas no banco de dados de forma a disponibilizar recursos para mineração desses dados na Memore-net e ao mesmo tempo reduzir a necessidade de intervenção humana no processo de identificação de correlações entre os dados, facilitando investigações que busquem responder o quanto o uso de JED pode favorecer o aprendizado dos alunos. Cabe enfatizar que o caso de uso UC01 indicado na Figura 1(a) permite ao docente importar para o banco de dados do JEDi todas as perguntas a serem utilizadas nas partidas do referido JED.

As telas do JEDi de escolha do Tema e do Avatar são ilustradas nas Figuras 2 e 3 respectivamente.

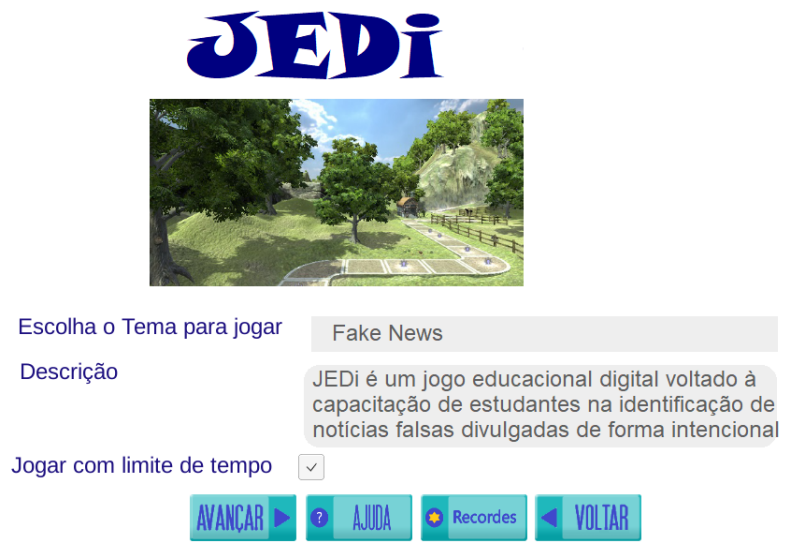

Figura 2: Tela de configuração do JEDi para a escolha do tema.

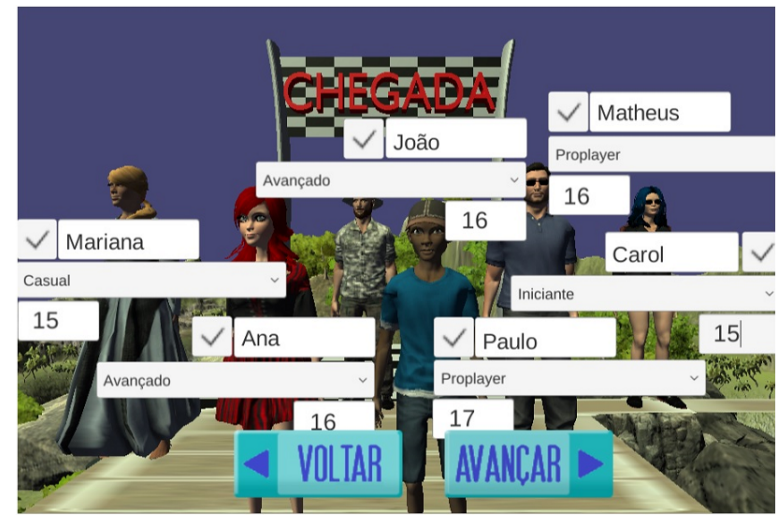

Figura 3: Tela de configuração do JEDi para a escolha do avatar. 
A Figura 4 (a) mostra um exemplo de pergunta realizada durante a execução do JEDi. No item (b) está a tela de finalização, no qual a pontuação e a posição do aluno na escola é mostrado.

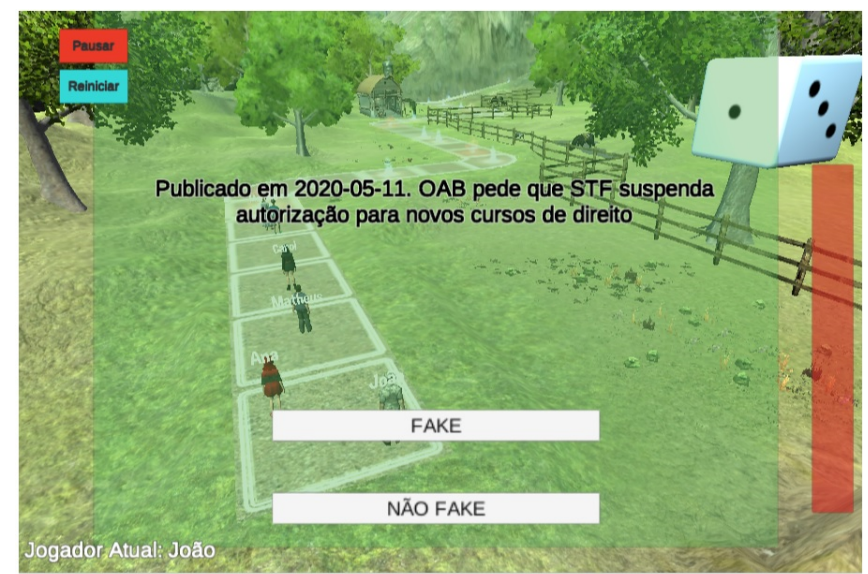

(a)

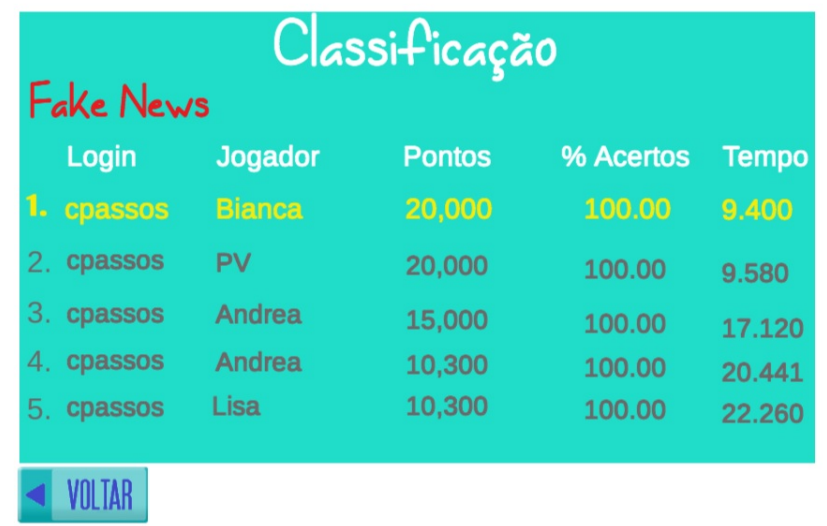

(b)

Figura 4: Telas do JEDi: (a) Perguntas; (b) Fim de partida.

Para a autoavaliação, o aluno deve escolher um dentre os cinco níveis organizados em ordem crescente de aptidão: noob (i.e., newbie, novato em inglês), iniciante, casual, avançado e proplayer. A nomenclatura adotada na denominação desses níveis procurou espelhar uma terminologia que fosse familiar aos alunos no universo dos jogos digitais modernos. Nos itens (a) e (b) da figura 3 encontram-se ilustradas, respectivamente, a interface principal do jogo e a tela apresentada ao final de cada partida, contendo a posição dos jogadores com melhor desempenho até então.

\section{Estudos de Caso}

A fim de buscar evidências experimentais que indiquem que os JED podem ser utilizados como ferramentas de apoio ao combate às fake news escritas na Língua Portuguesa, o presente trabalho realizou dois estudos de caso com o JEDi descritos na Seção 4.

O primeiro estudo foi desenvolvido junto a quarenta e três alunos na faixa de 14 a 21 anos 
do ensino médio de uma escola da rede particular de educação do município de Foz do Iguaçu no Paraná. O segundo foi realizado com 29 alunos na faixa de 20 a 31 anos da graduação de uma instituição pública federal do Rio de Janeiro. Para fins de simplificação do texto, as siglas EM (Ensino Médio) e ES (Ensino Superior) foram adotadas para denominar o primeiro e o segundo estudo de caso, respectivamente.

Com o objetivo de detalhar os estudos de caso realizados, esta seção está organizada em seis partes. A primeira descreve a metodologia aplicada na realização dos dois estudos de caso, reportando o fluxo de atividade executada. A segunda parte relata as características do conjunto de notícias fake e não fake que compõem a base de dados do JEDi. A terceira parte destaca as particularidades ocorridas na dinâmica de realização dos estudos de caso. Em seguida, a quarta parte descreve o tratamento realizado nos dados coletados pelo jogo durante as partidas jogadas nos estudos de caso. O desempenho dos discentes nas partidas jogadas e a efetividade do JEDi em apoiar a capacitação na identificação de fake news são apresentados e discutidos na quarta parte. Por fim, a quinta e última parte reporta e analisa os resultados da avaliação do jogo feita pelos estudantes.

\subsection{Metodologia Adotada}

A metodologia dos estudos de caso foi iniciada com o contato realizado junto às equipes diretivas das instituições envolvidas. Nesse trabalho, a expressão equipe diretiva refere-se, no caso do EM, ao grupo de profissionais composto pelo diretor, vice-diretor e coordenadores pedagógicos da escola (Krawczyk, 1999). No caso do ES, equipe diretiva foi utilizada como sinônimo das funções de direção de centro e coordenação de curso.

O objetivo do contato com ambas as equipes diretivas, do colégio e da instituição de ensino superior, foi firmar parceria e agendar reuniões para o planejamento da aplicação do JEDi. Por conta do isolamento social imposto pela COVID-19, todas as atividades envolvidas na pesquisa de ambos os estudos de caso foram realizadas com o apoio de uma sala virtual síncrona.

Para a realização dos estudos de caso, os pesquisadores executaram um conjunto de passos organizados no formato de processo, conforme disposto no fluxograma da Figura 5. Esse fluxograma foi modelado por meio de um diagrama de atividades da UML (Bezerra, 2007). Para organizar as atividades dos atores foram criadas três raias: uma para o desenho dos passos a serem executados com as equipes diretivas das instituições educacionais, outra para a equipe docente e uma última para os discentes. 


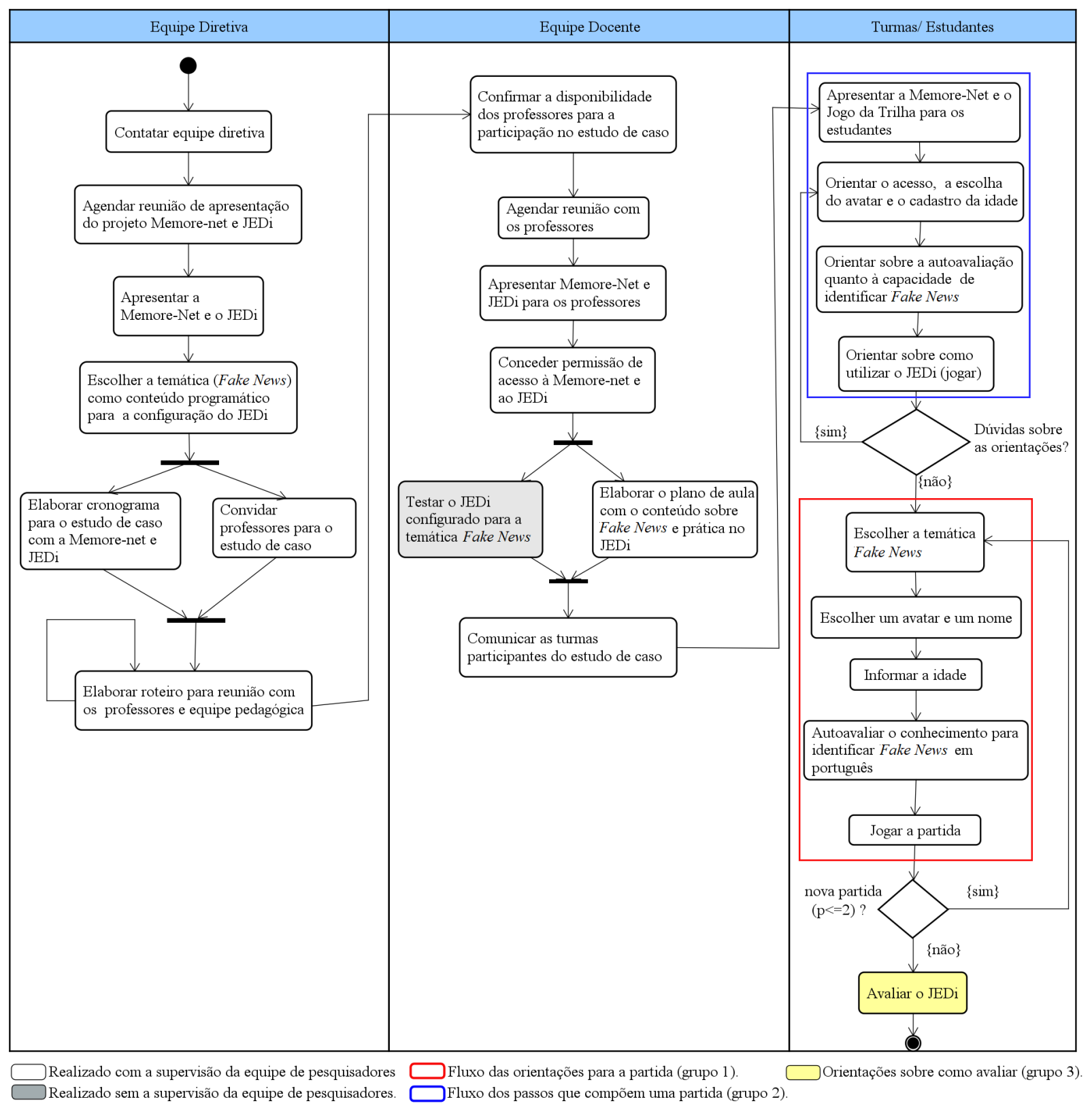

Figura 5: Fluxograma do processo dos estudos de caso. 
Na raia para a equipe diretiva, a primeira atividade do conjunto de passos foi a apresentação da rede social Memore-net e do JEDi. Na sequência, foi definida a temática de fake news, escritas em português, para a configuração do conteúdo do jogo. Também foram executados os passos da indicação dos docentes, das turmas, dos horários e da dinâmica de implementação por meio da elaboração de um cronograma. Por último, foi elaborado um roteiro para as reuniões com os professores das turmas que fizeram parte dos estudos de caso.

$\mathrm{Na}$ raia de atividades executadas em conjunto com os professores, os pesquisadores confirmaram a disponibilidade dos mesmos para a participação nos experimentos. Na sequência, foram realizadas reuniões para as apresentações da Memore-Net e JEDi, concessão das permissões de acesso a essas duas ferramentas, elaboração do plano de aula com o assunto fake news, orientações para o uso do JEDi e a testagem do jogo configurado para as notícias falsas e verdadeiras escritas em português. Por último, os professores comunicaram as turmas selecionadas que as mesmas fariam parte do estudo de caso sobre fake news.

$\mathrm{Na}$ raia turmas, as orientações aos estudantes foram organizadas em três grupos: (1) orientações sobre como acessar o JEDi; (2) orientações sobre a jogabilidade, ou seja, a utilização do jogo sob a supervisão dos pesquisadores; e (3) orientações sobre como avaliar o JEDi.

Nas orientações sobre como acessar o jogo, modeladas como atividades do grupo 1, foram apresentados a Memore-net e o JEDi. Na sequência, os estudantes receberam instruções sobre a forma de acesso, sobre a escolha de um avatar e sobre o registro da idade. Cada discente foi orientado sobre como informar o nível de autoavaliação de sua capacidade em identificar fake news antes de iniciar cada partida do jogo.

Para realizar a autoavaliação, os estudantes foram orientados a escolher em qual faixa de valores de acerto esperavam se enquadrar ao final de cada partida. Cada faixa estava associada a uma denominação comum encontrada em jogos envolvendo competição. Desta forma, no início de cada partida, os alunos deveriam escolher uma dentre as categorias indicadas na Tabela 2.

Tabela 2: Faixas de categorias utilizadas na autoavaliaçao.

\begin{tabular}{|c|c|}
\hline Categoria & Faixa de percentual de acertos \\
\hline Proplayer & $80 \%$ a $100 \%$ \\
\hline Avançado & $60 \%$ a $79 \%$ \\
\hline Casual & $40 \%$ a $59 \%$ \\
\hline Iniciante & $20 \%$ a $39 \%$ \\
\hline Noob & $0 \%$ a $19 \%$ \\
\hline
\end{tabular}

Ainda referente às orientações do grupo 1, os alunos foram informados sobre as regras de utilização, expressas em duas premissas básicas. A primeira era de que cada aluno deveria jogar, no mínimo, duas partidas. Tal restrição teve como objetivo assegurar que todos os alunos pudessem ser avaliados de forma longitudinal. A segunda premissa versava sobre o fato de que a primeira e a última partida jogadas por cada aluno seriam consideradas para avaliar, respectivamente, os desempenhos inicial e final do referido estudante na identificação de fake news.

Quanto às orientações referentes aos experimentos de utilização do JEDi, modeladas como atividades do grupo 2, os estudantes receberam o endereço de acesso à Memore-net, usuário e senha de login no JEDi. Conectados no jogo, os alunos selecionaram a temática fake news em português, escolheram e nominaram um avatar, informaram a idade, autoavaliaram o conheci- 
mento para identificar fake news e jogaram a partida em que analisaram como verdadeiras ou falsas as notícias do conjunto de perguntas.

As atividades do grupo 3 compreenderam as orientações sobre como cada aluno deveria avaliar o JEDi. Assim, após o encerramento da atividade de utilização do jogo, cada estudante foi orientado a responder a um instrumento de avaliação do jogo. As perguntas (expressas por meio de afirmações) foram adaptadas a partir da escala motivacional para materiais instrucionais. Essa escala utilizada foi proposta no trabalho de Savi et al. (2011). As perguntas do instrumento avaliativo foram organizadas em dimensões, conforme ilustrado na Tabela 3.

A fim de determinar o grau de concordância com as afirmações das dimensões avaliadas, cada aluno atribuiu uma nota. Essa mensuração utilizou a escala Likert proposta por Antonialli et al. (2017): -2 (discordo fortemente), -1 (discordo parcialmente), 0 (não concordo nem discordo), +1 (concordo parcialmente), +2 (concordo totalmente).

Tabela 3: Dimensões do JEDi avaliadas a partir da adaptação de Savi et al. (2011).

\begin{tabular}{|c|l|l|}
\hline Dimensão & Descrição & Exemplo de pergunta \\
\hline Atenção & $\begin{array}{l}\text { Obtenção e a manutenção da atenção na di- } \\
\text { nâmica do jogo. }\end{array}$ & $\begin{array}{l}\text { A variação, na forma/conteúdo aju- } \\
\text { dou a me manter atento ao jogo. }\end{array}$ \\
\hline Relevância & $\begin{array}{l}\text { Consiste na avaliação da importância do } \\
\text { conteúdo. }\end{array}$ & O conteúdo do jogo é relevante. \\
\hline Imersão & $\begin{array}{l}\text { Refere-se ao envolvimento, pleno e total, } \\
\text { com o jogo, por exemplo, diminuição a } \\
\text { consciência às ocorrências do entorno, al- } \\
\text { teração na noção de tempo, entre outros. }\end{array}$ & $\begin{array}{l}\text { Euão percebi o tempo passar en- } \\
\text { quanto jogava, quando vi o jogo } \\
\text { acabou. }\end{array}$ \\
\hline Interação Social & $\begin{array}{l}\text { Mensuração do sentimento de cooperação, } \\
\text { competição, conexão com outros jogadores, } \\
\text { entre outros. }\end{array}$ & $\begin{array}{l}\text { Percebi que o jogo permite interagir } \\
\text { com outras pessoas. }\end{array}$ \\
\hline Desafio & $\begin{array}{l}\text { Avaliação da compatibilidade dos desafios } \\
\text { do JEDi com o nível de habilidades do jo- } \\
\text { gador, ou seja, refere-se à mensuração do } \\
\text { quanto o jogo é desafiador para o público } \\
\text { alvo. }\end{array}$ & $\begin{array}{l}\text { Este jogo é adequadamente desafi- } \\
\text { ador para mim, as tarefas não são } \\
\text { muito fáceis nem muito difíceis. }\end{array}$ \\
\hline Divertimento & $\begin{array}{l}\text { Mensuração do quanto a partida foi praze- } \\
\text { rosa e divertida, merecendo a recomenda- } \\
\text { ção do JEDi aos amigos. }\end{array}$ & $\begin{array}{l}\text { Gostaria de utilizar este jogo nova- } \\
\text { mente. }\end{array}$ \\
\hline Competência & $\begin{array}{l}\text { Refere-se à avaliação do quanto o jogo } \\
\text { apoia o desenvolvimento de habilidades do } \\
\text { jogador. }\end{array}$ & $\begin{array}{l}\text { Conseguiria melhorar a capacidade } \\
\text { de reconhecer fake news. }\end{array}$ \\
\hline
\end{tabular}

\subsection{Base de Dados do JEDi}

O conjunto de perguntas do JEDi utilizado em ambos os estudos de caso foi carregado com 600 notícias publicadas entre março de 2017 e maio de 2020, oriundas de três agências de checagem de fatos brasileiras (Lupa, Aos Fatos e AFP) e de duas mídias renomadas ( $\mathrm{G} 1^{10}$ e $\mathrm{R} 7^{11}$ ).

\footnotetext{
${ }^{10}$ Portal G1 do grupo Globo

${ }^{11}$ Portal R7 do grupo Record
} 
Outrossim, vale ressaltar que a base de notícias do JEDi é atualizada de forma contínua ao longo do tempo. Essa atualização da base é feita a partir das notícias disponíveis em agências de checagem de fatos, ou seja, notícias que circulam nas redes sociais. O processo de recuperação e atualização da base de dados encontra-se descrito em Silva (2020). A atualização contínua da base de dados tem como objetivos: (1) estimular os alunos a se manterem informados sobre os acontecimentos no Brasil e no mundo; (2) manter os estudantes em contato com assuntos que, por estarem em evidência, tenham uma maior propensão a ser objetos de divulgação de fake news; (3) reduzir a probabilidade de que notícias repetidas sejam apresentadas aos discentes em partidas distintas, mitigando, assim, as chances de acerto por memorização. Desta forma, a probabilidade de cerca de $3 \%$ de que uma mesma notícia seja escolhida em duas partidas ${ }^{12}$ tende a ser reduzida na medida em que novas notícias sejam incorporadas à base de dados.

Na primeira carga da base de dados, todas as notícias recuperadas foram lidas, avaliadas e classificadas nas seguintes categorias temáticas: Política, Economia, Saúde Pública, Educação, Tecnologia, Segurança e Outras. Com o propósito de liberar o jogo para os dois primeiros estudos de caso, a base utilizada foi recuperada automaticamente, porém, classificada e validada manualmente. A Tabela 4 sumariza as notícias dessa base, apresentando-as de forma consolidada e segmentada por classificação temática e indicando as respectivas frequências absoluta $(n)$ e relativa $(\%)$ em cada segmento.

Tabela 4: Frequências absoluta (n) e relativa (\%) do conjunto de notícias segmentado pela classificação temática das notícias.

\begin{tabular}{|l|c|c|c|c|}
\hline \multirow{2}{*}{ Classificação } & \multicolumn{2}{|c|}{ Fake } & \multicolumn{2}{c|}{ não Fake } \\
\cline { 2 - 5 } & $\boldsymbol{n}$ & $\mathbf{\%}$ & $\boldsymbol{n}$ & $\mathbf{\%}$ \\
\hline Notícias sobre Política & 155 & $52 \%$ & 18 & $6 \%$ \\
\hline Notícias sobre Economia & 27 & $9 \%$ & 119 & $40 \%$ \\
\hline Notícias sobre Saúde Pública & 46 & $15 \%$ & 29 & $10 \%$ \\
\hline Notícias sobre Educação & 7 & $2 \%$ & 58 & $19 \%$ \\
\hline Notícias sobre Tecnologia & 3 & $1 \%$ & 34 & $11 \%$ \\
\hline Notícias sobre Segurança & 37 & $12 \%$ & 8 & $3 \%$ \\
\hline Notícias sobre outras Temáticas & 25 & $8 \%$ & 34 & $11 \%$ \\
\hline Total de Notícias & $\mathbf{3 0 0}$ & $\mathbf{1 0 0 \%}$ & $\mathbf{3 0 0}$ & $\mathbf{1 0 0 \%}$ \\
\hline
\end{tabular}

A Tabela 5 apresenta um resumo estatístico sobre a quantidade de caracteres e de palavras presentes nas notícias da base de dados em questão.

Tabela 5: Médias e desvios-padrão das quantidades de caracteres e de palavras presentes nas notícias.

\begin{tabular}{|l|c|c|c|c|}
\hline \multirow{2}{*}{ Características Observadas } & \multicolumn{2}{|c|}{ Fake } & \multicolumn{2}{c|}{ não Fake } \\
\cline { 2 - 5 } & média & desvio padrão & média & desvio padrão \\
\hline Quantidade de caracteres por notícia & 144,55 & 86,54 & 81,37 & 16,11 \\
\hline Quantidade de palavras por notícia & 24,2 & 15,76 & 14,05 & 2,8 \\
\hline
\end{tabular}

\footnotetext{
${ }^{12}$ Este cálculo foi baseado em um número médio de vinte notícias a que os alunos são apresentados a cada partida e no total de duas partidas, considerando a base de dados com 600 notícias utilizada nesta pesquisa.
} 


\subsection{Particularidades da Dinâmica de Execução dos Estudos de Casos}

As reuniões com as equipes diretivas das instituições seguiram uma dinâmica própria. No EM foram feitas duas reuniões com diretores. Em decorrência da pandemia da COVID-19, isolamento social e a mudança dos processos de ensino e aprendizagem, em um primeiro momento, a Direção mostrou preocupação com o volume de trabalho adicional aos professores. Para o estudo de caso ser autorizado e a parceria dos pesquisadores com o colégio ser firmada, foi necessária uma segunda reunião com a exposição detalhada da dinâmica do experimento com o JEDi.

No ES, o contato com a equipe diretiva foi mais simples, bastando apenas um comunicado sobre a dinâmica à coordenação de curso. O procedimento de comunicação aos atores envolvidos com o estudo de caso foi simplificado devido à proximidade dos pesquisadores com a instituição de ensino superior, em particular, com o curso de graduação.

Diferentemente do ocorrido com os alunos do ES, os alunos do EM se limitaram ao mínimo de duas partidas. Acredita-se que essa limitação ocorreu pelo fato do experimento ter sido realizado em dois tempos de quarenta e cinco minutos, no turno da aula. Embora esse tempo fosse suficiente para jogar mais de duas partidas, supõe-se que possa não ter ficado claro para os alunos que eles poderiam ter jogado mais partidas além do mínimo solicitado.

No experimento realizado no ES os alunos jogaram mais de duas partidas, pois jogaram em horários fora da sala de aula. Os estudantes receberam as orientações sobre como acessar o JEDi e as orientações de utilização do jogo. Ainda sob a supervisão dos pesquisadores, alguns alunos testaram acesso e jogaram a primeira partida. Dados a maturidade do público e o conhecimento de tecnologia (eram estudantes de Ciências Exatas e da Terra), foi indicado um período de quinze dias para utilizarem o JEDi de forma livre e autônoma. O processo dos estudos de caso se encerrou com a avaliação do JEDi. Os alunos do EM e ES foram estimulados pelos professores e pesquisadores a acessarem um formulário e avaliarem o jogo.

Após as partidas, todos os estudantes do EM responderam imediatamente à avaliação. No ES, a avaliação foi enviada quinze dias após os alunos terem sido apresentados ao JEDi. O processo de avaliação do ES precisou ser lembrado por três vezes para obter o engajamento dos alunos participantes.

\subsection{Pré-processamento dos Dados Coletados nas Partidas}

O JEDi coleta a resposta dada por cada jogador diante de cada notícia a ele apresentada em uma partida. Coleta também o tempo decorrido (em segundos) que o jogador leva para responder cada pergunta. Como a base de dados contém a informação do rótulo real de cada notícia (i.e., se a notícia é fake ou não fake), o JEDi computa como erro ou acerto a resposta dada por cada jogador a cada notícia a ele apresentada. De posse dessas informações, apurou-se o percentual de acertos e o tempo médio de resposta de cada jogador em cada partida.

Como no início de cada partida, cada jogador deve informar sua autoavaliação quanto à capacidade de identificar fake news, o JEDi dispõe dessa informação para ser analisada frente ao desempenho efetivamente obtido por cada jogador em cada partida. A fim de viabilizar a comparação direta entre a autoavaliação indicada pelo jogador e a avaliação realmente obtida por ele, foi necessário discretizar o atributo referente ao percentual de acerto, utilizando, para tanto, 
as mesmas faixas adotadas na autoavaliação (vide Tabela 2).

É importante registrar que dos 29 alunos do ES participantes, 12 não tiveram seus dados computados por terem classificado corretamente $100 \%$ das notícias a eles apresentadas. Tal exclusão teve como objetivo eliminar os alunos que não foram impactados pelo JEDi e que, portanto, poderiam introduzir algum viés na análise da efetividade do jogo. Assim, para a análise do ES, foram computados apenas os dados dos estudantes que tiverem diferença no desempenho entre a primeira e a última partida.

Além do percentual de acertos de cada jogador em cada partida, o JEDi armazena dois outros atributos quantitativos: o tempo médio de resposta obtido na partida e a idade do jogador. Para viabilizar o uso dessas informações na mineração de regras de associação voltada à avaliação do desempenho discente, optou-se por discretizar os atributos correspondentes. Para tanto, foi utilizado o método de Sturges (Goldschmidt et al., 2015).

Diante do interesse desta pesquisa em avaliar o efeito do uso do JEDi na identificação de fake news, optou-se por considerar apenas a primeira e a última partida jogada por cada jogador, desprezando os dados das demais partidas. Visando padronizar a análise dos dados nos dois estudos de caso, tal procedimento teve como objetivo assegurar que os dados do ES ficassem alinhados com o mesmo padrão de apenas duas partidas por jogador seguido pelo EM. A Tabela 6 apresenta um resumo estatístico dos dados após este tratamento.

Por fim, visando facilitar a aplicação das técnicas de mineração de dados, foi criado um novo atributo denominado capacidade crítica com os seguintes valores possíveis: aumentou, diminuiu e inalterada. Assim, para cada jogador, foi feita uma comparação entre os percentuais de acerto por ele obtidos na primeira e na última partida. Caso o percentual de acerto da última partida tenha sido maior que o da primeira partida, atribuiu-se valor aumentou para o atributo capacidade crítica. Caso o percentual de acerto da primeira partida tenha sido maior que o da última partida, atribuiu-se o valor diminuiu para o atributo capacidade crítica. No caso de percentuais iguais nas duas partidas, o atributo capacidade crítica recebeu o valor inalterada.

Tabela 6: Resumo estatístico dos dados coletados nas partidas, após terem sido pré-processados.

\begin{tabular}{|c|c|c|}
\hline Características Observadas & Média \pm DP (EM) & Média \pm DP (ES) \\
\hline Idade dos jogadores (anos) & $15,30 \pm 1,10$ & $22,30 \pm 2,50$ \\
\hline Tempo de resposta por pergunta (segundos) & $9,97 \pm 4,70$ & $8,11 \pm 4,28$ \\
\hline Tempo de resposta por partida (segundos) & $341,11 \pm 230,57$ & $208,69 \pm 80,75$ \\
\hline Acertos por partida (\%) & $69,50 \pm 29,00$ & $80,63 \pm 12,53$ \\
\hline
\end{tabular}

\subsection{Desempenho Discente}

O conjunto de dados, após a etapa de pré-processamento, foi utilizado para avaliar a evolução dos estudantes entre a primeira e última partida, indicando a possível melhoria do desempenho na identificação das notícias fake. Diversos resultados relacionados ao desempenho discente puderam ser apurados após a utilização do JEDi em ambos os estudos de caso. A seguir os principais deles encontram-se apresentados e comentados.

O gráfico de barras contendo as quantidades de erros e de acertos dos jogadores do EM e ES, distribuídas de acordo com a temática das perguntas, é apresentado na Figura 6. Por meio da leitura 
desse gráfico é possível notar que notícias fake relacionadas à tecnologia parecem mais difíceis de serem identificadas. Embora o número de acertos tenha sido maior no ES, houve semelhança com o estudo de caso do EM quanto à dificuldade para reconhecer as notícias fake relacionadas à tecnologia. Acredita-se que tal dificuldade seja decorrente da velocidade e dinamismo da evolução tecnológica nos dias atuais, tornando complexa a tarefa de opinar sobre a veracidade das notícias dessa categoria.

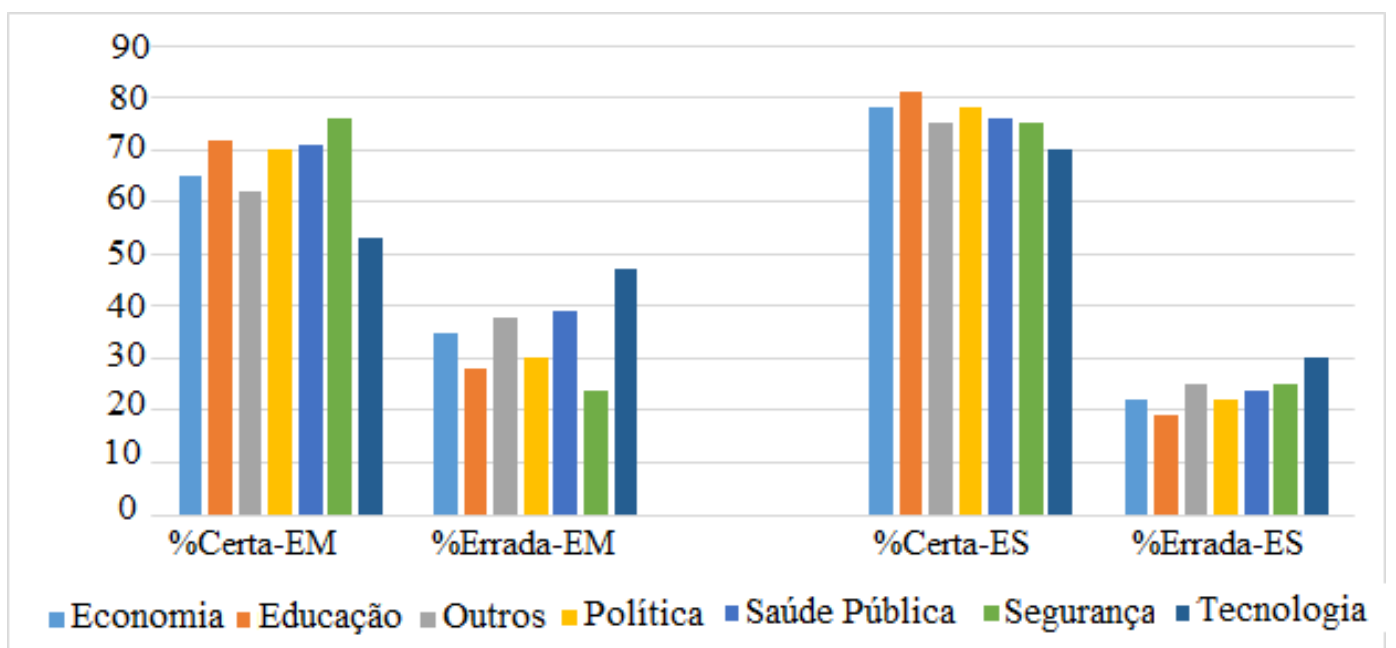

Figura 6: Acerto/erro dos estudantes do EM e ES com notícias classificadas por tema.

Na Figura 7, os gráficos (a) e (b) apresentam uma comparação entre a autoavaliação dos alunos do EM e ES, em relação à sua capacidade em identificar fake news e os resultados efetivamente obtidos por esses estudantes durante o jogo. Percebe-se, em ambos os níveis de ensino, uma clara divergência entre as impressões dos discentes quanto à sua capacidade de acerto e o seu desempenho apurado por meio do jogo.

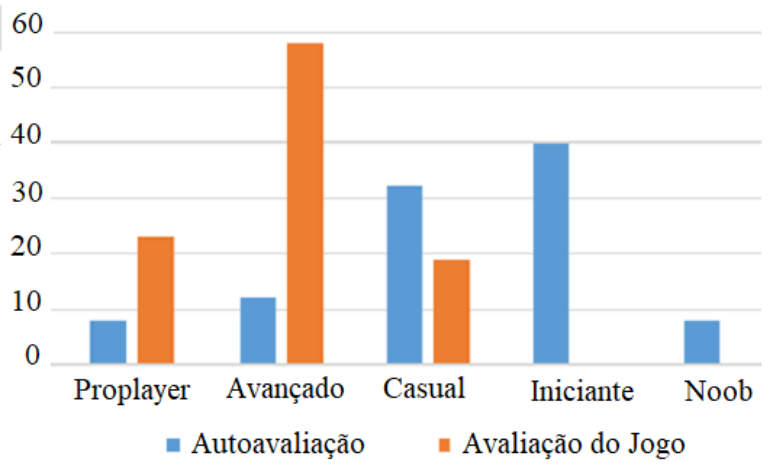

(a)

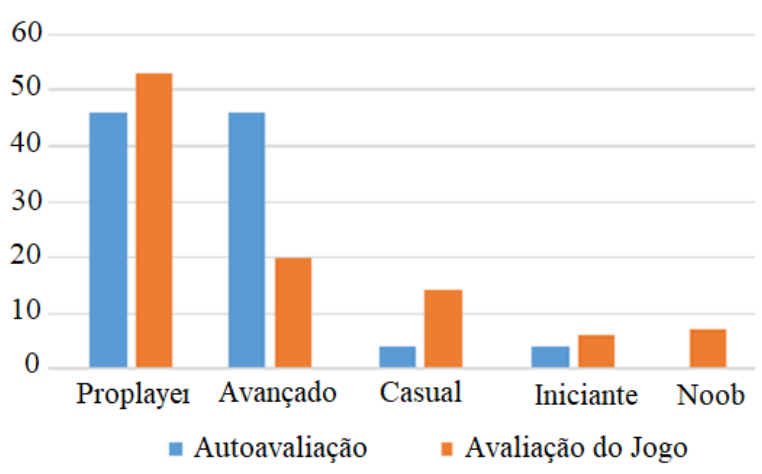

(b)

Figura 7: Autoavaliação versus desempenho real obtido por estudantes do EM (a) e do ES (b).

A Figura 8 ilustra o desempenho dos alunos do EM e do ES nas duas partidas analisadas. No EM percebeu-se um aumento no percentual de acertos e no tempo médio de resposta (Figuras 8(a) e 8(b), respectivamente), o que denota tanto uma melhoria na capacidade de identificação de fake news quando uma análise mais atenta e criteriosa das notícias. Resultado similar ocorreu 
com os estudantes do ES, que apresentaram evolução entre a primeira e última partida. No ensino superior percebe-se uma evolução do percentual de acertos mostrado na Figura 8(a) e uma estabilização no tempo médio de resposta exposto na Figura 8(b), o que pode denotar um conhecimento já solidificado na capacidade de identificação de fake news ou ainda a maior maturidade dos estudantes.

Em termos comparativos, percebe-se que o desempenho dos alunos do ES foi superior ao do EM. Tal resultado é coerente com a afirmação registrada em UNESCO (2016), de que o nível de instrução formal de um individuo está intimamente relacionado com a capacidade de reconhecer notícias falsas, denotando a importância da educação no contexto ao combate às fake news.

Para verificar a significância estatística dos resultados apresentados na Tabela 8(a), foi aplicado o teste de hipóteses $t$-Student em cada estudo de caso (Magalhães, 2010). Em ambos os casos, adotou-se nível de significância $\alpha=0,05$ e hipótese nula $H_{0}: O$ desempenho dos estudantes se manteve inalterado entre a primeira e a última partida. O p-valor encontrado para o EM foi 0,034 e para o ES foi 0,029, indicando a rejeição da $H_{0}$ nos dois cenários. Assim sendo, em termos estatísticos, pode-se afirmar que os estudantes, independente do nível de ensino, apresentaram melhoria na sua capacidade em identificar fake news. Os resultados da aplicação do teste apontam, portanto, para a efetividade do JEDi como instrumento de capacitação discente na identificação de fake news.

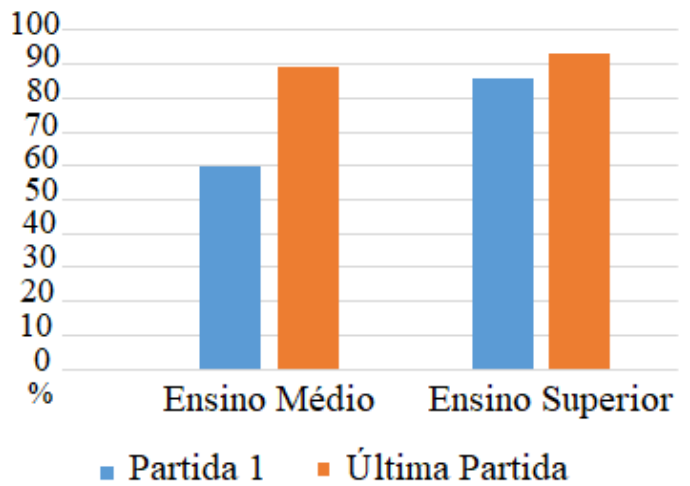

(a)

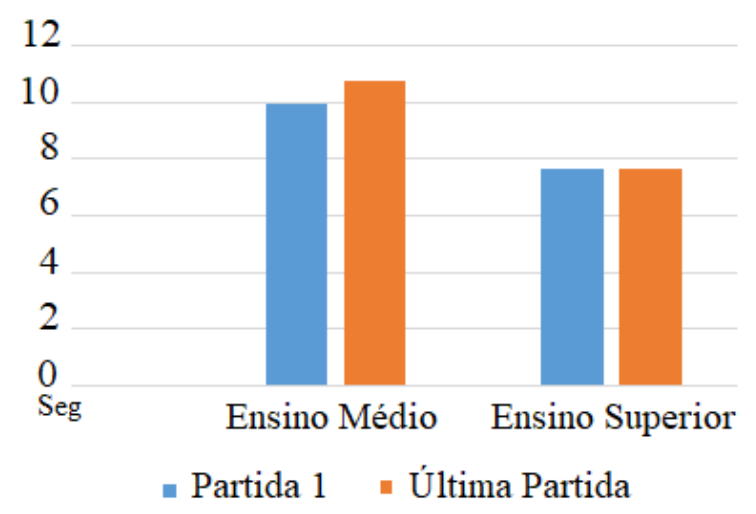

(b)

Figura 8: Resultados dos discentes, consolidados por desempenho em termos de: (a) percentual de acertos; e (b) tempo médio de resposta (seg).

Outra observação que merece destaque foi a capacidade dos alunos em perceber como fake algumas notícias cujo teor reflete situações absurdas, como a retratada na notícia "Publicado em 11/09/2018. Jovem se esfaqueia para provar que facada de Bolsonaro foi falsa e acaba morrendo.". Dos vinte e oito alunos do EM que foram confrontados com esta notícia apenas um deles (3\%) errou, ao indicá-la como não fake. Essa capacidade também foi observada no ES, em que ao serem confrontados com essas notícias falsas, de cunho aberrativo, houve $100 \%$ de acerto nesse tipo de notícia.

Algumas regras de associação foram identificadas com a aplicação do algoritmo descrito na Subseção 2.2. Três exemplos de regras identificadas no EM estão expostos na Tabela 7. O termo consequente das três regras apresentadas (i.e., a capacidade crítica aumentou) indica a ocorrência de melhoria da capacidade discente em diferenciar notícias fake das não fake da primeira para a 
última partida. Em conjunto, essas regras indicam, com elevada confiança, que alunos classificados no nível avançado pelo jogo, bem como discentes que se autoavaliam casuais ou iniciantes na primeira partida, tenderam a aumentar suas capacidades críticas.

Em termos específicos, segundo a regra $R_{1}, 78 \%$ dos casos em que o jogo avaliou o aluno do EM como avançado na primeira partida, o algoritmo detectou que houve a melhoria da capacidade crítica, de uma partida para outra. $\mathrm{Na} R_{2}$, em $100 \%$ das ocorrências em que o estudante se autoavaliou como casual, antes de iniciar a primeira partida, a capacidade crítica desses alunos aumentou nas segundas partidas. Por último, de acordo com a $R_{3}$, de forma análoga à $R_{2}$, é possível observar que para $80 \%$ dos casos em que o jogador se autoavaliou, na primeira partida, como iniciante, ele melhorou a sua capacidade de discernir entre notícias verdadeiras e falsas.

Tabela 7: Regras de associação identificadas a partir dos dados do EM.

\begin{tabular}{|c|c|c|c|}
\hline Regra & Exemplo de regras de associação identificadas & Suporte & Confiança \\
\hline$R_{1}$ & Avaliação do jogo $\left(1^{a}\right.$ partida $)=$ avançado => [Capacidade crítica aumentou] & $14 \%$ & $78 \%$ \\
\hline$R_{2}$ & Autoavaliação $\left(1^{a}\right.$ partida $)=$ casual => [Capacidade crítica aumentou] & $5 \%$ & $100 \%$ \\
\hline$R_{3}$ & Autoavaliação $\left(1^{a}\right.$ partida $)=$ iniciante => [Capacidade crítica aumentou] & $10 \%$ & $80 \%$ \\
\hline
\end{tabular}

Outras duas regras foram identificadas para o ES e estão dispostas na Tabela 8. Assim como ocorrido no estudo de caso do EM, essas regras indicam que a capacidade crítica dos alunos do ES também aumentou (i.e., nas duas regras, o termo consequente indica a ocorrência de melhoria da capacidade discente em diferenciar notícias falsas e verdadeiras da primeira para a última partida). Especificamente, segundo a regra $R_{1}, 100 \%$ das ocorrências em que o estudante se autoavaliou como iniciante, antes de iniciar a primeira partida, a capacidade crítica aumentou. De forma similar, a $R_{2}$ indica que $100 \%$ dos casos para os quais o jogador se autoavaliou como casual na primeira partida, a capacidade de discernir entre fake e não fake aumentou na última partida.

Tabela 8: Regras de associação identificadas a partir dos dados do ES.

\begin{tabular}{|c|c|c|c|}
\hline Regra & Exemplo de regras de associação identificadas & Suporte & Confiança \\
\hline$R_{1}$ & Autoavaliação $\left(1^{a}\right.$ partida $)=$ iniciante => [Capacidade crítica aumentou] & $20.83 \%$ & $100 \%$ \\
\hline$R_{2}$ & Autoavaliação $\left(1^{a}\right.$ partida $)=$ casual => [Capacidade crítica aumentou] & $20.83 \%$ & $100 \%$ \\
\hline
\end{tabular}

\subsection{Resultados da Avaliação do JEDi}

A Tabela 9 sumariza os dados do questionário aplicado durante a etapa de avaliação do jogo pelos estudantes do EM e do ES.

Na primeira coluna são apresentadas as dimensões avaliadas. A segunda apresenta as médias e desvios padrões dos graus de concordância informados pelos alunos EM ao responder às perguntas das respectivas dimensões. Na terceira coluna estão os dados do ES. As médias foram obtidas da seguinte forma: i) calculou-se a média aritmética dos graus de severidade atribuídos pelos avaliadores, por pergunta; e ii) posteriormente, calculou-se a média aritmética dos graus de severidade das perguntas que pertencem a uma mesma categoria.

Ao analisar os resultados das avaliações dos alunos do EM e do ES dispostos na Tabela 9, com exceção da "Interação Social", percebe-se que todas as dimensões tiveram avaliação média acima de zero, indicando uma tendência de avaliação positiva dos aspectos analisados. Cabe 
ressaltar, no entanto, que, diante dos valores de desvio padrão apresentados, percebe-se que as opiniões não se mostraram unânimes nas dimensões avaliadas. Acredita-se que essa falta de unanimidade seja decorrente de um elevado nível de exigência dos jovens em relação a jogos em geral.

Tabela 9: Médias dos graus de concordância das dimensões avaliadas.

\begin{tabular}{|c|c|c|}
\hline Dimensão avaliada & Média \pm DP (EM) & Média \pm DP (ES) \\
\hline Atenção & $0,46 \pm 1,10$ & $0,38 \pm 1,46$ \\
\hline Relevância & $1,13 \pm 0.96$ & $1,46 \pm 0,78$ \\
\hline Imersão & $0.38 \pm 1,26$ & $0,46 \pm 1,33$ \\
\hline Interação Social & $-0,44 \pm 1,41$ & $-0,38 \pm 1,89$ \\
\hline Desafio & $0,69 \pm 1,26$ & $0,42 \pm 1,42$ \\
\hline Divertimento & $0,75 \pm 1,19$ & $0,79 \pm 1,17$ \\
\hline Competência & $1,31 \pm 0,79$ & $0,38 \pm 1,33$ \\
\hline
\end{tabular}

A baixa avaliação dos aspectos ligados à "Interação Social", tanto pelos estudantes do EM quanto do ES, era esperada, uma vez que a versão do jogo utilizada não viabilizava a realização de partidas com jogadores simultâneos. As sugestões quanto à interação entre os jogadores, indicadas por esses alunos, foram acatadas e uma nova versão encontra-se disponível. Nela é possível jogar em rede, em grupos de seis participantes que competem entre si.

Outras duas dimensões se destacam pela boa avaliação: a "Relevância" para estudantes do EM e ES e a "Competência" para os alunos do EM. Enquanto a primeira reflete a consciência discente com relação à importância do conteúdo tratado pelo JEDi, a segunda revela o reconhecimento dos alunos quanto ao potencial do jogo em aumentar sua capacidade em identificar fake news.

Após a aplicação do instrumento de avaliação, os alunos emitiram alguns feedbacks voltados à melhoria do jogo. Entre os principais, podem ser destacadas três sugestões:

(1) "Eu acho que o design poderia ser melhor trabalhado. Além disso, acho importante a criação de mais sentenças sobre 'fake news', para que em uma próxima partida as mesmas não se repitam. Mas eu amei a proposta do jogo e acho que mais temas poderiam ser incorporados!"(EM);

(2) "[...] o jogo poderia ser um pouco mais curto. Como o jogo fala de notícias, um tempo de duração muito grande fica cansativo"(EM);

(3) Sugestão de revisão na forma de pontuar as jogadas. "A pontuação do jogo acaba sendo maior para o jogador que consegue responder mais notícias sem errar. Ou seja, quem conseguir tirar os menores números nos dados responderá mais notícias, por andar em mais casas, e terá maiores chances de atingir uma pontuação maior."(ES).

Os estudantes foram estimulados a comentar quais características permitiram identificar notícias falsas. A seguir estão destacados alguns dos retornos obtidos:

(1) "Na maioria das noticias falsas existiam muitos erros gramaticais e ortográficos e também muitas delas eram absurdas, [...] tinham pouquíssimas chances de serem reais." (EM); 
(2) "Principalmente a linguagem. Quando é uma notícia verdadeira é sempre impessoal, buscando não ser tendencioso. As fake news (não sempre, claro) geralmente te conduzem a uma opinião moldada." (EM);

(3) "Possuíam conteúdo sensacionalistas e de cunho extremista, apresentando muitas vezes visões parciais da realidade." (ES).

Para finalizar, os participantes elencaram aspectos positivos ou relevantes do jogo, sendo alguns apresentados a seguir:

(1) "[...] eu achei interessante, várias coisas que eu achava fake não eram ou vice versa e também o negócio de chegar até o final é como se fosse um desafio, dá mais vontade de jogar!!" (EM);

(2) “Joguei 3 vezes [...]. Muito interativo. Amo esse tipo de jogo!.” (EM);

(3) "O jogo é divertido de se jogar [...]."(ES).

De forma geral, os resultados observados neste estudo contêm indícios que apontam para uma resposta positiva à questão de pesquisa quanto à possibilidade de uso de $J E D$ para capacitação de estudantes na identificação de fake news escritas em Português.

\section{Considerações Finais}

Uma das formas de combate às fake news é capacitar pessoas para identificá-las por meio de Jogos Educacionais Digitais (JED). Entretanto, até onde foi possível observar diante do levantamento bibliográfico realizado neste estudo, os JED utilizados para esse tipo de capacitação não dispõem de notícias escritas na Língua Portuguesa. Com o objetivo de suprir esta lacuna, o presente artigo propôs o JEDi, uma versão do "Jogo da Trilha" que exercita a identificação de fake news escritas em Português, além de oferecer suporte para mineração e análise de dados sobre o desempenho de seus jogadores.

Para avaliar a efetividade do JEDi na capacitação de estudantes em identificar fake news, foram realizados dois estudos de caso, um no ensino médio (EM), com quarenta e três alunos de uma escola da rede privada de educação do município de Foz do Iguaçu e outro no ensino superior (ES) com vinte e nove alunos de uma instituição pública do município do Rio de Janeiro.

Para realização dos estudos de caso, a presente pesquisa se propôs a uma estruturação do fluxo de atividades no formato de metodologia para o uso do JEDi. A metodologia proposta destaca-se como uma das principais contribuições deste trabalho, uma vez que facilita a realização do experimento, proporcionando maior clareza e coerência do propósito da aprendizagem e das atividades a serem executadas, agilidade da dinâmica de utilização do jogo e organização do uso do JEDi como objeto de suporte à aprendizagem.

No estudo de caso do EM foi possível perceber uma clara divergência entre as impressões iniciais dos discentes, via autoavaliação, quanto à sua capacidade de acerto e o seu desempenho 
apurado por meio do jogo. Além disso, destaca-se a evolução do desempenho individual dos alunos nas partidas, evidenciada pelo aumento no percentual de acertos, o que denota uma melhoria do desempenho discente de uma partida para outra. Os estudantes do ES tiveram excelente desempenho já na primeira partida indicando a importância da educação e cultura no combate às fake news.

Cabe ressaltar ainda que, a partir de uma pesquisa de avaliação respondida pelos alunos ao final dos estudos de caso, constatou-se que, na percepção dos estudantes, o jogo proposto apresenta um elevado grau de adequação ao seu propósito. Quanto à indicação da necessidade de melhoria dos aspectos de interação social reportada pelos alunos, foi desenvolvida e já se encontra disponível para download uma nova versão do JEDi que permite múltiplos jogadores participarem em rede e competirem entre si.

Em suma, o objetivo do presente trabalho foi alcançado, uma vez que, em ambos os estudos de caso, foram realizados testes estatísticos e obtidas evidências experimentais quantitativas e qualitativas de que o uso do JEDi pode atender o propósito de contribuir para melhoraria da capacidade discente na identificação de fake news escritas em Português.

Entre os trabalhos futuros, pretende-se desenvolver novos estudos de caso de forma a amadurecer a metodologia proposta. Além disso, testar a nova versão que permite grupos de jogadores competirem remotamente entre si. Outro ponto a ser trabalhado será a análise mais criteriosa da interface homem-máquina com foco na melhoria do desempenho do carregamento gráfico em memória e nas imagens do tabuleiro. Na versão dois do JEDi também espera-se aplicar os resultados de duas pesquisas em andamento, uma que fará, de forma automática, a atualização e classificação das novas notícias inseridas na base do jogo e a outra que insere tutores inteligentes que apoiarão e mediarão a aprendizagem e as dificuldades dos estudantes em identificar fake news escritas em Português, funcionalidade útil, principalmente, para o ensino médio. Além disso, pretende-se realizar um estudo comparativo do JEDi com JED nas dimensões de avaliação propostas por Savi et al. (2011). Espera-se que tal estudo forneça indicações de melhoria das interfaces humanocomputador do JEDi.

\section{Agradecimentos}

Ao Colégio Bertoni de Foz do Iguaçu/PR e ao Instituto Militar de Engenharia do Rio de Janeiro/RJ, incluindo suas equipes diretiva e docente, além de seus discentes, pela participação na pesquisa.

\section{Artigo Premiado Estendido}

Esta publicação é uma versão estendida do $1^{\circ}$ melhor artigo do Simpósio Brasileiro de Informática na Educação (SBIE 2020), intitulado "Jogos Educacionais Digitais como Ferramentas de Apoio à Capacitação Discente na Identificação de Fake News Escritas em Língua Portuguesa: Um Estudo de Caso”, DOI: 10.5753/cbie.sbie.2020.401. 


\section{Referências}

Abreu, P. M. R., Berwanger, P. M., \& Costa, R. B. (2018). Gameficação e as fakenews: uma análise do jogo cheque isso! Projeção e Docência, 9(2), 167-177. [GS Search]

Agrawal, R., Imieliński, T., \& Swami, A. (1993). Mining association rules between sets of items in large databases. Sigmod Rec., 22(2), 207-216. doi: 10.1145/170036.170072 [GS Search]

Ajao, O., Bhowmik, D., \& Zargari, S. (2019). Sentiment aware fake news detection on online social networks. In ICASSP 2019 - 2019 IEEE International Conference on Acoustics, Speech and Signal Processing (ICASSP) (pp. 2507-2511). doi: 10.1109/ICASSP.2019.8683170 [GS Search]

Antonialli, F., Antonialli, L., \& Antonialli, R. (2017, 12). Usos e abusos da escala likert: estudo bibliométrico nos anais do enanpad de 2010 a 2015. , 22(4), 1-19. [GS Search]

Auberry, K. (2018). Increasing students' ability to identify fake news through information literacy education and content management systems. The Reference Librarian, 59(4), 179-187. doi: 10.1080/02763877.2018.1489935 [GS Search]

Bezerra, E. (2007). Princípios de análise e projeto de sistema com uml (Vol. 2). Rio de Janeiro: Elsevier. [GS Search]

Campan, A., Cuzzocrea, A., \& Truta, T. M. (2017). Fighting fake news spread in online social networks: Actual trends and future research directions. In 2017 IEEE International Con on Big Data (Big Data) (pp. 4453-4457). doi: 10.1109/BigData.2017.8258484 [GS Search]

Castelo, S., Almeida, T., Elghafari, A., Santos, A., Pham, K., Nakamura, E., \& Freire, J. (2019). A topic-agnostic approach for identifying fake news pages. In Companion Proceedings of The 2019 World Wide Web Conference (pp. 975-980). New York, NY, USA: ACM. doi: $10.1145 / 3308560.3316739$ [GS Search]

Conroy, N., Rubin, V., \& Chen, Y. (2015). Automatic deception detection: Methods for finding fake news. Association for Information Science and Technology, 52, 1-4. doi: 10.1002/pra2.2015.145052010082 [GS Search]

Empirico, S. (1997). Hipotiposes pirrônicas livro i (tradução de danilo marcondes). O que nos faz pensar, 9(12), 115-122. Retrieved from http://www.oquenosfazpensar.fil.puc-rio.br/ index.php/oqnfp/article/view/130

Faceli, K., Lorena, A., Gama, J., \& De Carvalho, A. (2011). Inteligência artificial: uma abordagem de aprendizado de máquina. LTC. Retrieved from https://books.google.com.br/ books?id=4DwelAEACAAJ

Flintham, M., Karner, C., Bachour, K., Creswick, H., Gupta, N., \& Moran, S. (2018). Falling for fake news: Investigating the consumption of news via social media. In Proceedings of the 2018 CHI Con on Human Factors in Computing Systems (pp. 376:1-10). New York, NY, USA: ACM. doi: 10.1145/3173574.3173950 [GS Search]

Francesco, N. N., \& Leone, S. D. (2020). 1. educação midiática contra"fake news". Revista Científica UMC, 5(1), 1-15. Retrieved from http://seer.umc.br/index.php/revistaumc/article/ view/955/766

Freire, P., \& Goldschmidt, R. (2020). Combatendo fake news nas redes sociais via crowd signals implícitos. In Anais do XVI Encontro Nacional de Inteligência Artificial e Computacional (pp. 424-435). Porto Alegre, RS, Brasil: SBC. doi: 10.5753/eniac.2019.9303 [GS Search]

Freire, P. M. S., \& Goldschmidt, R. R. (2019). Uma introdução ao combate automático às fake news em redes sociais virtuais. In Tópicos de Gerenciamento de Dados e Informação (pp. 


\section{8-67). Fortaleza, CE, Brazil: SBC. doi: 10.5753/sbbd.2019 [GS Search]}

Golbeck, J., Mauriello, M., Auxier, B., Bhanushali, K. H., Bonk, C., Bouzaghrane, M. A., .. . Visnansky, G. (2018). Fake news vs satire: A dataset and analysis. In Proceedings of the 10th ACM Con on Web Science (pp. 17-21). New York, NY, USA: ACM. doi: 10.1145/3201064.3201100 [GS Search]

Goldschmidt, R., Bezerra, E., \& Passos, E. (2015). Data mining: Conceitos, técnicas, algoritmos, orientações e aplicações. Rio de Janeiro: Elsevier.

Krawczyk, N. (1999). A gestão escolar: um campo minado... Análise das propostas de 11 municípios brasileiros. Educação Sociedade, 20(67), 112-149. doi: 10.1590/S010173301999000200005 [GS Search]

Magalhães, A. C. P., M. N.; Lima (2010). Noções de probabilidade e estatística. São Paulo: USP.

Marwick, A., \& Lewis, R. (2017). Media manipulation and disinformation online. New York: Data \& Society Research Institute. Retrieved from https://datasociety.net/wp-content/uploads/ 2017/05/DataAndSociety_MediaManipulationAndDisinformationOnline-1.pdf

McGuire, W. J. (1964). Some contemporary approaches. In L. Berkowitz (Ed.), Advances in experimental social psychology (Vol. 1, pp. 191-229). Elsevier. doi: 10.1016/S00652601(08)60052-0 [GS Search]

Mejova, Y., \& Kalimeri, K. (2020). Advertisers jump on coronavirus bandwagon: Politics, news, and business. ArXiv, 2003.00923, 1-11. Retrieved from https://arxiv.org/pdf/2003.00923 .pdf

Musgrove, A. T., Powers, J. R., Rebar, L. C., \& Musgrove, G. J. (2018). Real or fake? resources for teaching college students how to identify fake news. College \& Undergraduate Libraries, 25(3), pp. 243-260. doi: 10.1080/10691316.2018.1480444 [GS Search]

Mustafaraj, E., \& Metaxas, P. T. (2017). The fake news spreading plague:was it preventable? In Web Science Con (p. 235-239). doi: 10.1145/3091478.3091523 [GS Search]

Nascimento, C. E. G. (2020). Fake news, mentira organizada e educação: Uma reflexão a partir do pensamento de hammah arendt. Revista Docência e Cibercultura, 4, 243-263. doi: 10.12957/redoc.2020.47553 [GS Search]

Passos, C., Fernandes, I., \& Goldschmidt, R. (2019). Elaboração e avaliação de projeto de aprendizagem apoiado em jogos educacionais digitais: Um relato de experiência com alunos em alfabetização. In Proceedings Brazilian Symposium on Computers in Education (Simpósio Brasileiro de Informática na Educação - SBIE) (p. 674). SBC. doi: 10.5753/cbie.sbie.2019.674 [GS Search]

Paz, D. P., Franco, M., de Castro Bertagnolli, S., \& Costa, H. J. (2018). Desenvolvimento e avaliação de um jogo digital educacional sobre aspectos socioculturais de países hispano falantes. In Proceedings Brazilian Symposium on Computers in Education (Simpósio Brasileiro de Informática na Educação - SBIE) (p. 795). doi: 10.5753/cbie.sbie.2018.795 [GS Search]

Reis, J. C. S., Correia, A., Murai, F., Veloso, A., \& Benevenuto, F. (2019). Explainable machine learning for fake news detection. In Proceedings of the 10th ACM Conference on Web Science (p. 17-26). New York, NY, USA: ACM. doi: 10.1145/3292522.3326027 [GS Search]

Rodrigues, J. G. (2013). O relativismo acerca da verdade refuta-se a si mesmo? Revista Portuguesa de Filosofia, 69(3/4), 777-806. Retrieved from http://www.jstor.org/stable/ 23785891 
Roozenbeek, J., \& van der Linden, S. (2019a). The fake news game: actively inoculating against the risk of misinformation. Journal of Risk Research, 22(5), 570-580. doi: 10.1080/13669877.2018.1443491 [GS Search]

Roozenbeek, J., \& van der Linden, S. (2019b, 25). Fake news game confers psychological resistance against online misinformation. Palgrave Communications, 5(1), 65. doi: 10.1057/s41599-019-0279-9 [GS Search]

Savi, R., Wangenheim, C., \& Borgatto, A. (2011). Um modelo de avaliação de jogos educacionais na engenharia de software. In Proceedings of the 25th Brazilian Symposium on Software Engineering (SBES). SBC. doi: 10.1109/SBES.2011.27 [GS Search]

Sharma, K., Qian, F., Jiang, H., Ruchansky, N., Zhang, M., \& Liu, Y. (2019). Combating fake news: A survey on identification and mitigation techniques. ACM Trans. Intell. Syst. Technol., 10(3), 21:1-21:42. doi: 10.1145/3305260 [GS Search]

Shu, K., Sliva, A., Wang, S., Tang, J., \& Liu, H. (2017). Fake news detection on social media: A data mining perspective. SIGKDD Explor. Newsl., 19(1), 22-36. doi: 10.1145/3137597.3137600 [GS Search]

Silva, F. (2020). FakeNewsSetGen: um processo para construção de datasets que viabilizem a comparação entre métodos de detecção de fake news baseados em diferentes demandas de informação. Mestrado em sistemas e computação, Instituto Militar de Engenharia (IME), Rio de Janeiro, Brasil. Retrieved from http://repositorio.mar.mil.br/handle/ripcmb/844824

Sponholz, L. (2009). O que é mesmo um fato? conceitos e suas conseqüências para o jornalismo. In Revista galáxia (p. 56-69). PUC-SP. Retrieved from https://revistas.pucsp.br/index.php/ galaxia/article/view/2642/1683

UNESCO (2016). Marco de avaliação global da alfabetização midiática e informacional (ami): disposição e competências do país. Cetic.br. Retrieved from https://nic.br/media/docs/ publicacoes/8/246398POR.pdf

UNESCO (2019). Jornalismo, fake news \& desinformação - manual para educação e treinamento em jornalismo. Author. Retrieved from http://portaldobibliotecario.com/wp-content/ uploads/2020/06/ManualFakeNews.pdf

Vosoughi, S., Mohsenvand, M. N., \& Roy, D. (2017). Rumor gauge: Predicting the veracity of rumors on twitter. ACM Trans. Knowl. Discov. Data, 11(4), 50:1-50:36. doi: 10.1145/3070644 [GS Search]

Wang, P., Angarita, R., \& Renna, I. (2018, April). Is this the era of misinformation yet: Combining social bots and fake news to deceive the masses. In Companion Proceedings of the The Web Con 2018 (pp. 1557-1561). Republic and Canton of Geneva, Switzerland: International World Wide Web Con Steering Committee. doi: 10.1145/3184558.3191610 [GS Search]

Zhou, X., \& Zafarani, R. (2020). Fake news: A survey of research, detection methods, and opportunities. ACM Computing Surveys, 53(5), 1-40. doi: 10.1145/3395046 [GS Search]

Zhou, X., Zafarani, R., Shu, K., \& Liu, H. (2019). Fake news: Fundamental theories, detection strategies and challenges. In Proceedings of the Twelfth ACM International Con on Web Search and Data Mining (pp. 836-837). New York, NY, USA: ACM. doi: 10.1145/3289600.3291382 [GS Search] 